\title{
Continuous measurements of isotopic composition of water vapour on the East Antarctic Plateau
}

\author{
Mathieu Casado $^{1,2}$, Amaelle Landais ${ }^{1}$, Valérie Masson-Delmotte ${ }^{1}$ Christophe Genthon $^{4,5}$, Erik Kerstel $^{2,3}$, \\ Samir Kassi ${ }^{2}$, Laurent Arnaud ${ }^{4,5}$, Ghislain Picard ${ }^{4,5}$, Frederic Prie ${ }^{1}$, Olivier Cattani ${ }^{1}$, Hans-Christian Steen-Larsen ${ }^{6}$, \\ Etienne Vignon $^{4,5}$, and Peter Cermak ${ }^{7}$ \\ ${ }^{1}$ Laboratoire des Sciences du Climat et de l'Environnement - IPSL, UMR 8212, CEA-CNRS-UVSQ, Gif-sur-Yvette, France \\ ${ }^{2}$ CNRS, LIPHY, 38000 Grenoble, France \\ ${ }^{3}$ Université Grenoble Alpes, LIPHY, 38000 Grenoble, France \\ ${ }^{4}$ Université Grenoble Alpes, LGGE, 38041 Grenoble, France \\ ${ }^{5}$ CNRS, LGGE, 38041 Grenoble, France \\ ${ }^{6}$ Centre for Ice and Climate, University of Copenhagen, Copenhagen, Denmark \\ ${ }^{7}$ Department of Experimental Physics, Faculty of Mathematics, Physics and Informatics, Comenius University, \\ Mlynska dolina F2, 84248 Bratislava, Slovakia
}

Correspondence to: Mathieu Casado (mathieu.casado@gmail.com)

Received: 5 January 2016 - Published in Atmos. Chem. Phys. Discuss.: 21 March 2016

Revised: 24 May 2016 - Accepted: 21 June 2016 - Published: 13 July 2016

\begin{abstract}
Water stable isotopes in central Antarctic ice cores are critical to quantify past temperature changes. Accurate temperature reconstructions require one to understand the processes controlling surface snow isotopic composition. Isotopic fractionation processes occurring in the atmosphere and controlling snowfall isotopic composition are well understood theoretically and implemented in atmospheric models. However, post-deposition processes are poorly documented and understood. To quantitatively interpret the isotopic composition of water archived in ice cores, it is thus essential to study the continuum between surface water vapour, precipitation, surface snow and buried snow.

Here, we target the isotopic composition of water vapour at Concordia Station, where the oldest EPICA Dome C ice cores have been retrieved. While snowfall and surface snow sampling is routinely performed, accurate measurements of surface water vapour are challenging in such cold and dry conditions. New developments in infrared spectroscopy enable now the measurement of isotopic composition in water vapour traces. Two infrared spectrometers have been deployed at Concordia, allowing continuous, in situ measurements for 1 month in December 2014-January 2015. Comparison of the results from infrared spectroscopy with laboratory measurements of discrete samples trapped using cryo-
\end{abstract}

genic sampling validates the relevance of the method to measure isotopic composition in dry conditions. We observe very large diurnal cycles in isotopic composition well correlated with temperature diurnal cycles. Identification of different behaviours of isotopic composition in the water vapour associated with turbulent or stratified regime indicates a strong impact of meteorological processes in local vapour/snow interaction. Even if the vapour isotopic composition seems to be, at least part of the time, at equilibrium with the local snow, the slope of $\delta \mathrm{D}$ against $\delta^{18} \mathrm{O}$ prevents us from identifying a unique origin leading to this isotopic composition.

\section{Introduction}

Ice cores from polar ice sheets provide exceptional archives of past variations in climate, aerosols and global atmospheric composition. Amongst the various measurements performed in ice cores, the stable isotopic composition of water (e.g. $\delta^{18} \mathrm{O}$ or $\delta \mathrm{D}$ ) provides key insights in past polar climate and atmospheric water cycle. The atmospheric processes controlling this signal have been explored throughout the past decades using present-day monitoring data. Based on the sampling of precipitation or surface snow, relationships be- 
tween precipitation isotopic composition and local temperature have been identified since the 1960s and understood theoretically to reflect atmospheric distillation processes (Dansgaard, 1964; Lorius et al., 1969). Nevertheless, there is both observational and modelling evidence that the isotopetemperature relationship is not stable in time and space (Jouzel et al., 1997; Masson-Delmotte et al., 2008). The variation in the isotope-temperature relationship has been explained by the isotopic composition of precipitation being sensitive to changes in condensation vs. surface temperatures, to changes in evaporation condition and transport paths and to changes in precipitation intermittency (Charles et al., 1994; Fawcett et al., 1997; Krinner et al., 1997; LeGrande and Schmidt, 2006; Masson-Delmotte et al., 2011; Werner et al., 2011). While complex, these processes can be tracked using second-order isotopic parameters such as d-excess, which preserve information on evaporation conditions (Jouzel et al., 2013; Landais et al., 2008), and they are accounted for by atmospheric models equipped with water stable isotopes (Risi et al., 2010; Schmidt et al., 2005; Werner et al., 2011).

The variations of $\mathrm{d}$-excess and some variations in $\delta^{18} \mathrm{O}$ are due to the different influences of equilibrium fractionation and diffusion driven kinetic fractionation processes at each step of the water mass distillation trajectory. Specific limitations exist for the representation of the isotopic fractionation at very low temperature. Equilibrium fractionation coefficients have been determined either by spectroscopic calculations (Van Hook, 1968) or by laboratory experiments (Ellehøj et al., 2013; Majoube, 1971; Merlivat and Nief, 1967), with significant discrepancies at low temperatures. Molecular diffusivities have mainly been measured at $20^{\circ} \mathrm{C}$ (Cappa et al., 2003; Merlivat, 1978), but recent experiments have shown that temperature can have a strong impact on these coefficients (Luz et al., 2009).

Another source of uncertainty for the climatic interpretation of ice core records arises from poorly understood postdeposition processes. Indeed, the isotopic signal of initial local snowfall can be altered through wind transport and erosion, which are strongly dependent on local and regional topography, and can produce artificial variations in ice core water stable isotopes caused by gradual snow dune movement (Ekaykin et al., 2002, 2004; Frezzotti et al., 2002). Moreover, it is well known that the initial isotopic signal associated with individual snowfall events is smoothed in firn, a process described as "diffusion" (Johnsen et al., 2000; Neumann and Waddington, 2004). This diffusion occurs through isotopic exchanges between surface water vapour and snow crystals during snow metamorphism (Waddington et al., 2002). "Diffusion lengths" have been identified based on spectral properties of ice core records and shown to depend on several processes: wind transport and erosion will alter the surface composition with a very strong influence of orography, and diffusion through the pores of the snow firn smooths the signal as does metamorphism of the crystals (Schneebeli and Sokratov, 2004). Finally, there are hints based on high-resolution isotopic measurements performed near snow surface of potential alteration of the initial precipitation isotopic composition (Hoshina et al., 2014; Sokratov and Golubev, 2009; Steen-Larsen et al., 2014a). This motivates investigations of the isotopic composition not only of precipitation and surface snow but also of surface water vapour.

Atmospheric monitoring in extreme polar climatic conditions remains challenging. Supersaturation generates frost deposition, which can bias temperature and humidity measurements, and low vapour contents are often outside of range of commercial instruments. As specific humidity is under 1000 ppmv on the central Antarctic plateau, measuring the isotopic composition of surface water vapour requires either very long cryogenic trapping (typically $10 \mathrm{~h}$ at $20 \mathrm{~L} \mathrm{~min}^{-1}$ ) to collect enough material for offline (mass spectrometric or laser-based) isotopic analyses or very sensitive online (laser-based) instruments able to produce accurate in situ isotopic measurements.

Recent developments in infrared spectroscopy now enable direct measurements of isotopic composition of the vapour in the field, without time-consuming vapour trapping. With careful calibration methodologies, these devices provide accuracies comparable with those of mass spectrometers (Bailey et al., 2015; Tremoy et al., 2011) and have already been used for surface studies in the Arctic region (Bonne et al., 2015, 2014; Steen-Larsen et al., 2014a).

The goal of our study is first to demonstrate the capability to reliably measure the isotopic composition of central Antarctic surface water vapour during summer, second to investigate the magnitude of its diurnal variations, in comparison with the corresponding results from central Greenland (Steen-Larsen et al., 2013), and third to highlight the impact of a intermittently turbulent boundary layer on the isotopic composition variations.

We focus on Concordia station, at the Dome $\mathrm{C}$ site, where the oldest Antarctic ice core record, spanning the last 800000 years, has been obtained (EPICA, 2004). During the last 20 years, the French-Italian Concordia station has been progressively equipped with a variety of meteorological monitoring tools, documenting vertical and temporal variations in atmospheric water vapour (Ricaud et al., 2012). During summer, meteorological data depict large diurnal cycles in both surface air temperature and humidity (Genthon et al., 2013), which may result from either boundary layer dynamics and/or air-snow sublimation/condensation exchanges.

During the Antarctic summer of 2006-2007, cold trap samplings of water vapour were performed. Here, we report for the first time the results of this preliminary study together with continuous measurements performed during the austral summer of 2014-2015 using laser instruments with a specific methodology for low-humidity calibration, as well as new cold trap sampling for laboratory measurements.

This manuscript is organized in two main sections to highlight the two different aspects of the study. First, Sect. 2 describes the technical aspect: the site, the material deployed 

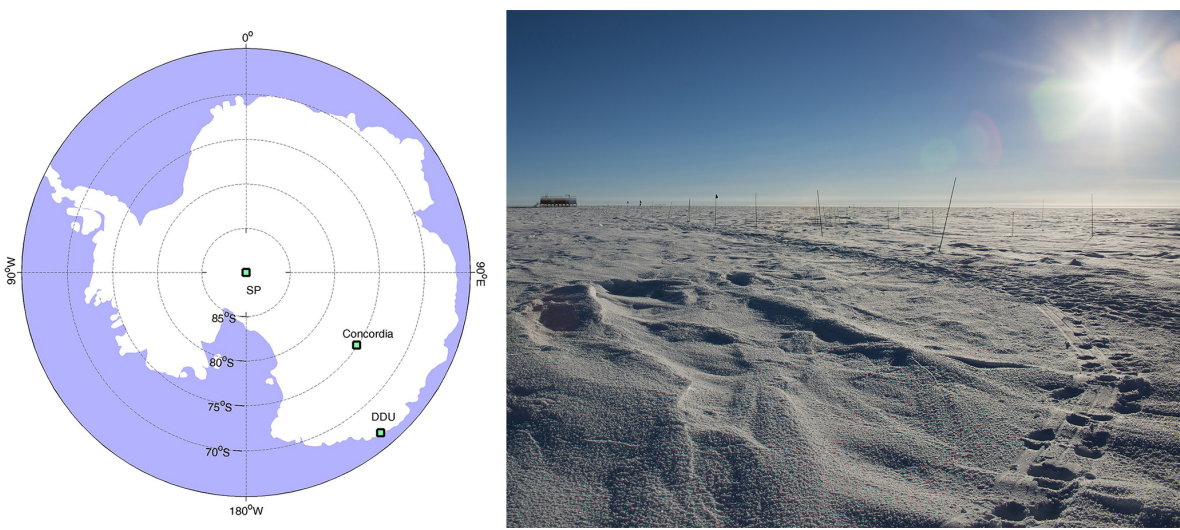

Figure 1. Left: map of Antarctica showing the location of Concordia, Dumont d'Urville station (DDU) and the South Pole (SP). Right: picture of the area from the top of the underground shelter where the instrument was located, looking toward the clean area.

and the applied methods, with a focus on calibration in order to assess the technical reliability of such methods for sites as cold as the Antarctic Plateau. Section 3 reports the scientific aspect of the results, with first a focus on the relevance of infrared spectroscopy compared to cryogenic trapping, second a description of the diurnal to intra-seasonal surface vapour isotopic variations and third an analysis of the origin of the vapour. We conclude and discuss outlooks for this work in Sect. 4.

\section{Technical challenges}

\subsection{Sampling site}

Concordia station is located near the top of Dome C at $75^{\circ} 06^{\prime} 06^{\prime \prime} \mathrm{S}-123^{\circ} 23^{\prime} 43^{\prime \prime} \mathrm{E}, 3233 \mathrm{~m}$ above sea level and $950 \mathrm{~km}$ from the coast. While the local mean temperature is $-54.3^{\circ} \mathrm{C}$, it was $-32.4^{\circ} \mathrm{C}$ during the campaign of $2014 / 2015$, reaching a maximum value of $-24.5^{\circ} \mathrm{C}$. Ice core data suggest an average annual accumulation of $2.7 \pm 0.7 \mathrm{~g} \mathrm{~cm}^{-2} \mathrm{yr}^{-1}$ (Genthon et al., 2015; Petit et al., 1982; Röthlisberger et al., 2000).

The first cold trap vapour sampling campaign was performed in summer 2006-2007. The second field campaign took place from 24 December 2014 to 17 January 2015.

The spectrometers for the 2014/2015 campaign were installed in an underground shelter located $800 \mathrm{~m}$ upwind from the station, therefore protected from the fumes of the power generator of the station (discussed in Sect. 2.5). Such underground shelter allows us to avoid any impact of the monitoring structure on the wind field and possible sampling artefacts. The area around the shelter is characterized by few sastrugi, none higher than $20 \mathrm{~cm}$ (Fig. 1). A clean area of $12 \mathrm{~m}^{2}$ with no sastrugi was marked around the inlets. We decided to point the inlets toward the dominant wind in order to prevent artefacts from condensation or evaporation from the protec- tion of the inlet or the pole holding it. Indeed, frost formation was observed on the protective foam and pole.

Together with our water vapour isotopic data, we use meteorological observations from the lowest level of the $45 \mathrm{~m}$ meteorological profiling system at Dome C (Genthon et al., 2013). The profiling system was located at proximity with the spectrometers. The temperature observations on the $45 \mathrm{~m}$ profiling system are made in aspirated shields and thus not affected by radiation biases. Genthon et al. (2011) demonstrated that when the wind speed is below $5 \mathrm{~m} \mathrm{~s}^{-1}$, radiation biases are very significant and can reach more than $10^{\circ} \mathrm{C}$ in conventional (non-wind-ventilated) shields. Temperature is measured using HMP155 thermohygrometers, while wind speed and direction are measured using Young 05103 and 05106 aerovanes. Elevation above the snow surface was $3.10 \mathrm{~m}$ for the wind and $2.58 \mathrm{~m}$ for temperature in 2014 2015. This will be henceforth commonly referred as the $3 \mathrm{~m}$ level. Further details on the observing system, instruments, sampling and results are available in previous publications (Genthon et al., 2013, 2010). Surface temperature is measured with a Campbell scientific IR120 infrared probe. The probe is located at $2 \mathrm{~m}$ height and uses upwelling infrared radiation and the temperature of the detector to compute the temperature of the surface of the snow. The uncertainty of the surface temperature measurement is around $\pm 1{ }^{\circ} \mathrm{C}$, which is mainly due to unknown and possibly varying emissivity of the snow (Salisbury et al., 1994).

\subsection{Water vapour isotope monitoring}

Two infrared spectrometers were used to measure continuously the isotopic composition of water vapour pumped $2 \mathrm{~m}$ above the snow surface: a cavity ring-down spectrometer (CRDS) from Picarro (L2130-i) and a high-finesse water isotope spectrometer (HiFI) based on the technique of optical feedback cavity-enhanced absorption spectroscopy (OFCEAS) developed in LIPhy (Laboratoire Interdisci- 


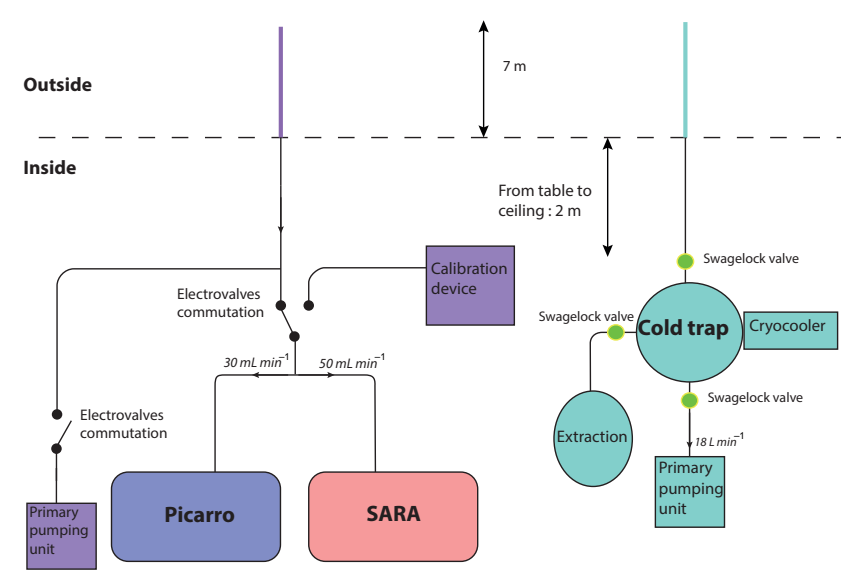

Figure 2. Schematics of the experimental set-up implied in the water vapour isotopic composition monitoring.

plinaire de Physique), Grenoble, France (Landsberg et al., 2014), as described on Fig. 2.

Both instruments are based on a general technique of cavity-enhanced absorption spectroscopy (Romanini et al., 2014). This is essentially a long-path-length optical detection technique that increases the sensitivity of detection of molecules in the optical cavity by folding the optical beam path between two (or three) highly reflective mirrors. The commercial Picarro spectrometer is based on nearinfrared continuous-wave cavity ring-down spectroscopy (CW-CRDS) (Crosson, 2008). It has proven to be a fairly robust and reliable system, delivering good-precision isotopic measurements at concentration (water mixing ratio) values between 1000 and 25000 ppmv.

The HiFI spectrometer also operates in the near-infrared region of the spectrum but uses OFCEAS (Romanini et al., 2014). In the case of the HiFI spectrometer, the optical path length was increased by about 1 order of magnitude to $45 \mathrm{~km}$. This optimizes the spectrometer for oxygen-18 isotopic measurements with a precision better than $0.05 \%$ at a water mixing ratio around 500 ppmv (Landsberg et al., 2014). The HiFI spectrometer was shown to be able to reach this level of performance also in Antarctica during a 3-week campaign at the Norwegian station of Troll (Landsberg, 2014). Unfortunately, during the current campaign at Dome $\mathrm{C}$ the spectrometer had to operate in a noisy environment. The system was not isolated from vibrations of several vacuum pumps in the shelter and an accidental resonance did perturb the phase control. This resulted in a baseline noise level more than one order higher than normal, which created a corresponding increase of the error on the isotope ratio measurements. At this level of noise, the Picarro measurements turned out to be more precise than the HiFI measurements. It is for this reason that the latter were only used as an independent tool to check on the absolute values from Picarro measurements.
All time series shown hereafter were obtained with the Picarro spectrometer.

The two instruments were connected through a common heated inlet consisting of a $1 / 4$ in copper tube. The internal pumps of each instrument pumped the outside vapour through the common inlet and into the respective cavities. The fluxes generated by the instruments were small enough not to interact with one another, as attested by stable pressure in the cavities of both instruments. The length of this common inlet (approximately $10 \mathrm{~m}$ long) caused a response delay of approximately $2 \mathrm{~min}$ for the humidity signal. Memory effects caused by interactions between the water vapour and the inside of the tubes introduce different delays for different isotopes. In the case of high-resolution data, artificial d-excess can be produced as the memory effect of HDO is substantial larger than $\mathrm{H}_{2}^{18} \mathrm{O}$ (Steen-Larsen et al., 2014b). However, our measurements were averaged over $1 \mathrm{~h}$ thereby removing this effect. No sign of condensation in the inlet was observed during the whole campaign.

\subsection{Allan variance analyses}

The measurements of isotopic composition with an acquisition time of approximately $1 \mathrm{~s}$ have a standard deviation of $10 \%$ of $\delta \mathrm{D}$ and of $2 \%$ of $\delta^{18} \mathrm{O}$ at approximately $500 \mathrm{ppmv}$ (Fig. 3). Infrared spectrometers typically produce data perturbed by different kinds of noise: one is noise due to frequency instabilities of the laser, temperature and mechanical instabilities of the cavity, temperature and pressure of the sampled gas, electronic noise and residual optical interference fringes on the spectrum baseline. The noise, usually predominantly white noise, can be significantly reduced through time averaging; for instance, with an acquisition time of $2 \mathrm{~min}$, we decrease the standard deviation to $1.3 \%$ for $\delta \mathrm{D}$ and $0.2 \%$ for $\delta^{18} \mathrm{O}$.

With increasing integration time, one expects the precision of the measurements to initially improve, due to the reduction of white noise, up to the point where instrumental drift becomes visible. The so-called Allan-Werle plot shows the overall expected precision as a function of integration time (Fig. 3).

Long-term laboratory measurement of a standard was carried out at a humidity of $506 \pm 3 \mathrm{ppmv}$ in order to reproduce the range of the expected humidity for Concordia station. Stable humidity production for $13 \mathrm{~h}$ was realized using the calibration device described in the next section and in the Supplement 1 . The standard deviation of $\delta \mathrm{D}$ follows the optimum line almost up to $4 \mathrm{~h}$ integration time. The standard deviation of $\delta^{18} \mathrm{O}$ does not follow the optimum profile after $100 \mathrm{~s}$ but still drops continuously over almost $2 \mathrm{~h}$. These measurements confirm the reliability of the Picarro L2130i even at low humidity and justify the use of such an instrument in this campaign. The integration time providing the ultimate precision could not be achieved because of the lack of a vapour generator stable for more than $13 \mathrm{~h}$. At other hu- 


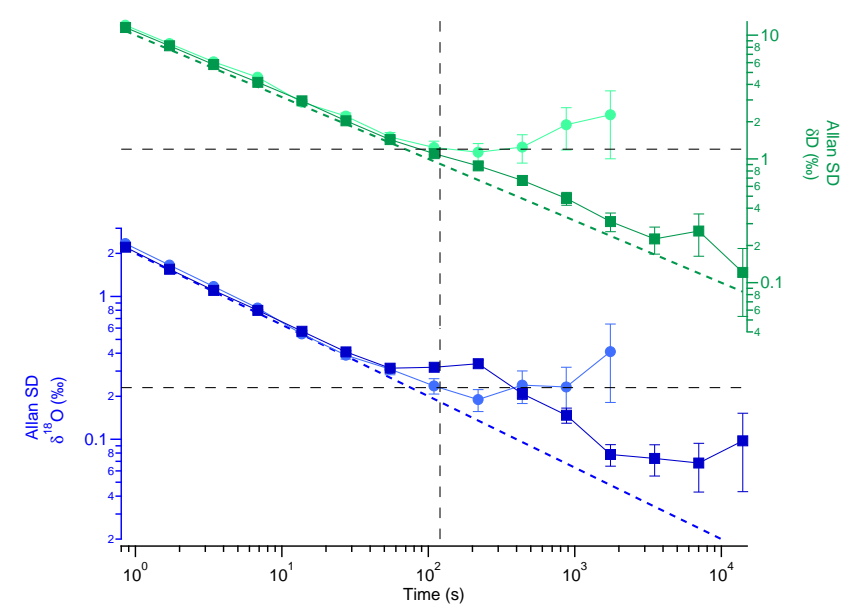

Figure 3. Allan variance plots for laboratory long-term standard measurement (dark squares) and for field long-term standard measurement (light circles) for $\delta \mathrm{D}$ (Top, green) and for $\delta^{18} \mathrm{O}$ (bottom, blue). Dash lines correspond to the quantum limit on $N^{-1 / 2}$ for each composition.

midity levels, we observe similar profiles with an increasing initial precision as the moisture content increases (not shown).

In the field, we performed calibrations lasting up to $90 \mathrm{~min}$, as a trade-off between instrument characterization and measurement time optimization. This, however, is not long enough to accurately estimate the rise of uncertainty due to instrumental drift but does allow us to assess the ultimate precision for the instruments under realistic field conditions. The Allan variance was thus calculated from field Picarro calibration data, at 450 ppmv. From this analysis, we conclude that $2 \mathrm{~min}$ appear to provide an optimal integration time, associated with an ultimate precision of the spectrometer of $0.2 \%$ for $\delta^{18} \mathrm{O}$ and $1.1 \%$ for $\delta \mathrm{D}$ (black dashed lines on Fig. 3). This test could not be performed at other humidities.

\subsection{Calibrations}

Calibration of the spectrometer is crucial in order to be able to express the measurement results with confidence on the international VSMOW2-SLAP2 (Standard Mean Ocean Water 2 and Standard Low Antarctic Precipitation 2) isotope scale (IAEA, 2009). Calibrations have been reported to vary between instruments and calibration systems, as well as over time. Tremoy et al. (2011) highlighted the importance of calibration for Picarro analysers under $10000 \mathrm{ppmv}$ with biases up to $10 \%$ or $\delta \mathrm{D}$ and of $1 \%$ ofor $\delta^{18} \mathrm{O}$ at volume mixing ratios (VMRs) down to 2000 ppmv. Protocols have been developed and adapted for calibration under Greenland ice sheet summer (Steen-Larsen et al., 2013) and south Greenland year-round conditions (Bonne et al., 2014) with good performance attested from parallel measurements of PICARRO and LGR analysers for humidity above 2000 ppmv. At VMRs below 2000 ppmv, much larger errors can be expected without calibrating the instruments.

For this field season, we have followed the classical calibration protocols with (1) a study of the drift of the instrument, (2) a linearity calibration using two working standards whose isotopic values were established in the laboratory vs. SMOW and SLAP and (3) a study of the influence of humidity on the isotopic value of the water vapour. At very lowhumidity levels (below $2000 \mathrm{ppmv}$ ), standard calibration devices (such as the SDM from Picarro) are not able to generate stable constant humidity. Here, we expected humidity levels below $1000 \mathrm{ppmv}$ and therefore we could not use standard water vapour generator and had to develop our own device inspired from the device developed by Landsberg (2014) and described in detail in the Supplement Sect. 1.

The calibration protocol for type (1) calibration relies on the measurement of one standard at one humidity level (the average of the expected measurement) twice a day for $30 \mathrm{~min}$ in order to evaluate the mean drift of the infrared spectrometer. Standard values of the drift on a daily basis should not exceed $0.3 \%$ in $\delta^{18} \mathrm{O}$ and $2 \% o$ in $\delta \mathrm{D}$. The calibration protocol for type (2) calibration relies on the measurement of two standards whose isotopic compositions bracket the one measured in order to evaluate the response of the infrared spectrometer compared to the SMOW-SLAP scale (thereafter isotope-isotope response). Typical isotope-isotope slope is between 0.95 and $1.05 \% \circ \%{ }^{-1}$ for $\delta^{18} \mathrm{O}$ and for $\delta \mathrm{D}$. The calibration protocol for type (3) calibration relies on the measurements of one standard at different levels of humidity in order to evaluate the response of the infrared spectrometer to humidity (thereafter isotope-humidity response). Type (2) and type (3) calibration can only be realized once a week provided type (1) calibration has validated the drift of the instrument was within acceptable values (below excess $0.3 \%$ o in $\delta^{18} \mathrm{O}$ and $2 \%$ in $\delta \mathrm{D}$ ). For temperate range where humidity is important (above $5000 \mathrm{ppmv}$ ), it is possible to consider a linear relationship for the isotope-humidity response; for dryer situations (below $5000 \mathrm{ppmv}$ ), the isotope-humidity response requires at least a quadratic relationship.

The three types of calibrations were performed in the field and in the laboratory prior and after field work. It was particularly important to add laboratory calibrations (especially for drift of the instrument) in addition to field calibrations because of the short season and lack of dry air at the beginning of the season, in particular to strengthen the results from type (2) and (3) calibrations as we will present in the following.

In order to evaluate the performances of our spectrometer, all type of calibrations were performed in the laboratory at different humidities (from 100 to $1000 \mathrm{ppmv}$ ) and repeated on five occasions in a time span of 4 weeks with two standards: $\mathrm{UL1}\left(\delta^{18} \mathrm{O}=-54.30 \%\right.$ and $\left.\delta \mathrm{D}=-431.1 \% \circ\right)$ and NEEM $\left(\delta^{18} \mathrm{O}=-33.56 \%\right.$ and $\delta \mathrm{D}=-257.6 \%$ ) . We estimate the mean drift for a period of 1 month (type 1) by com- 


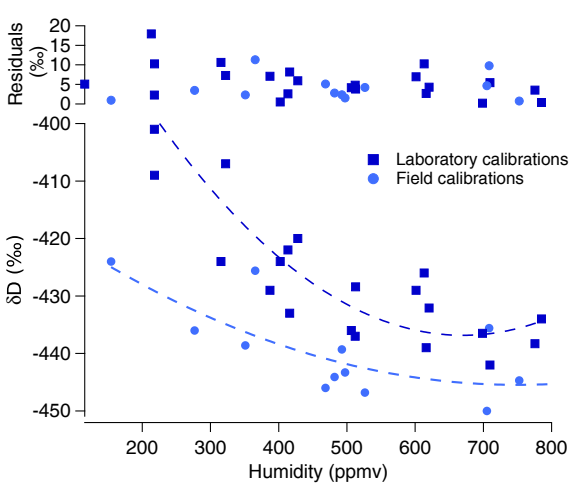

(a)

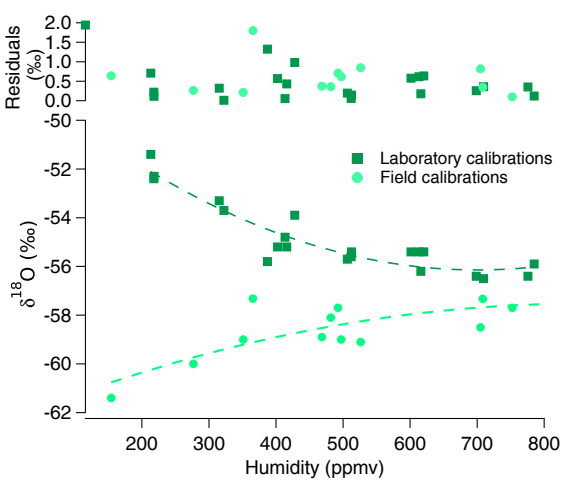

(b)

Figure 4. Measured isotopic composition for (a) $\delta \mathrm{D}$ and (b) $\delta^{18} \mathrm{O}$ using the PICARRO spectrometer for a fixed humidity: light circles are field calibration points, dark squares are laboratory calibration points, the dashed lines are the fit with a quadratic function and at the top are the residuals compared to the fit for the entire series.

Table 1. Average residuals compared to the quadratic fit toward humidity of laboratory (five sets) and field calibrations for different humidity levels for the Picarro; cf. Fig. $4 a$ and b.

\begin{tabular}{llrrrr}
\hline Laboratory & Humidity (ppmv) & 200 & 400 & 600 & 800 \\
calibrations & $\delta$ D residuals (\%o) & 10.1 & 4.9 & 6.0 & 3.1 \\
& $\delta^{18}$ O residuals (\%o) & 0.3 & 0.7 & 0.5 & 0.3 \\
\hline \multirow{2}{*}{ Field } & Humidity (ppmv) & 150 & 350 & 480 & 710 \\
calibrations & $\delta$ D residuals (\%o) & 1.0 & 6.8 & 2.9 & 5.1 \\
& $\delta^{18}$ O residuals (\%o) & 0.6 & 1.0 & 0.5 & 0.4 \\
\hline
\end{tabular}

paring the offset of the isotopic composition over the five occurrences. For the isotope-isotope slope, we obtain standard values around $0.95 \% \% \%^{-1}$. We evaluate the laboratory isotope-humidity response by comparing the measured value of the isotopic composition to the value of humidity. Each independent set of calibrations (each week) can be fitted by a quadratic function with a small dispersion of the data points (inferior to $2 \%$ for $\delta \mathrm{D}$ and $0.2 \%$ for $\delta^{18} \mathrm{O}$ ). Different calibration sets performed over different days show dispersion due to the instrument drift. We observe a much larger dispersion for $\delta \mathrm{D}$ than for $\delta^{18} \mathrm{O}$, in particular at low concentration (200 ppmv) due to the combined action of the drift and of the noise of the instrument (see Table 1). Note that the low residuals for the field calibration at $150 \mathrm{ppmv}$ are an artefact due to few measurements at this humidity. The average drift observed combining the offset isotopic composition over 1 month is slightly under $1 \% \circ$ in $\delta^{18} \mathrm{O}$ and reaches $8 \%$ in $\delta \mathrm{D}$ (type 1 calibration).

Field calibration could only be performed after 7 January when the dry air bottle was delivered to Concordia. Then, two calibrations per day were realized as follows: 30 min calibration, 30 min measurements of outside air and 30 min calibration. As the data are interpolated on an hourly resolution, this procedure prevents gaps in the data. Altogether, 20 calibrations were achieved from 7 to 17 January with two working standards. These logistical issues require adjustment to the calibration procedure described above. Because type (1) calibration could not be performed during the field campaign, we use the drift evaluated from the laboratory calibrations to bracket the maximum drift expected over a period of 1 month. This results in an important increase of the uncertainty of the measurement of $\delta^{18} \mathrm{O}$ from $0.2 \%$ optimal value from the Allan variance) to $1 \%$ (estimated from the drift of the instrument during the laboratory type (1) calibration) and in $\delta \mathrm{D}$ from 1.3 to $6 \%$.

Type (2) calibration was realized on the field using two working standards calibrated against VSMOW-SLAP: NEEM and UL1 at the end of the campaign. Because the vapour isotopic composition at Dome $\mathrm{C}$ was much lower than expected (well below the SLAP isotopic composition), in order to properly estimate the isotope-isotope response of the instrument it was necessary to evaluate the relevance of the correction obtained from the field calibration. This is described in Sect. 2.6 and required to produce new standards with isotopic composition below the SLAP value. As described in Sect. 2.6, we validated that even by calibrating the isotope-isotope response of the instrument above the SLAP composition, the linearity of the instrument was good enough to extend the calibration down at least to $-80 \%$ in $\delta^{18} \mathrm{O}$.

As it was not possible to perform relevant ramps of humidity within 1 day, type (3) calibration was realized by merging all calibration realized on the field into one series (Fig. 4, light colour points). This merged field calibration set provides with an estimate of the linear correction to be applied on the measured humidity (cf. Supplement 2 ). The merged field calibration series also documents the nonlinearity of the instrument as a function of the background humidity level and is used to correct the values of $\delta \mathrm{D}$ and $\delta^{18} \mathrm{O}$ measurements in water vapour. The laboratory and field calibrations do not match. Calibrations realized in the lab and in the field have been reported to differ (Aemisegger et al., 2012), which rules out the use of pre-campaign laboratory calibrations, 
even though laboratory calibration is still useful for providing insight into the minimum error to be expected during the field campaign. There is no indication from Aemisegger et al. (2012) that opposite trends were obtained during the different calibrations. We checked the possibility that this behaviour could be linked with the remaining water content of the air carrier as it occurred for Bonne et al. (2014) e.g. at low humidities. For both field and laboratory calibrations, we used Air Liquid Alphagaz 1 air with a remaining water content below 3 ppmv. One possible explanation for the opposite trend on the field compared to laboratory calibrations could be an extraordinary isotopic composition of the air carrier from the dry air cylinder during the field campaign. However, we do not believe the air carrier is responsible for this opposite trend. First, we realized a calculation of the isotopic composition of the 3 ppmv of water remaining in the cylinder necessary to explain the difference between the field and the laboratory calibrations trends. The calculation is the average of the isotopic composition weighted by the water content between the remaining 3 ppmv (unknown isotopic composition to be determined) and the water vapour generated by the calibration device (known humidity and isotopic composition). It is not possible to find one unique value matching the system and the range of calculated values spans between $\delta^{18} \mathrm{O}=-450 \%$ and $\delta^{18} \mathrm{O}=-650 \%$. This range is beyond anything observed from regular use of air carrier cylinder. Second, the same cylinder was used during another campaign and a similar feature was not observed (not shown). Finally, we observe a very good agreement between the results from the Picarro and the cryogenic trapping data (see Sects. 2.6 and 3.1) with a difference of $1.16 \%$ for $\delta^{18} \mathrm{O}$ using the field calibrations. If we use the laboratory calibrations, this would create a much larger difference (above $5 \%$ difference in $\delta^{18} \mathrm{O}$ ) which validates the calibration procedure and the use of the field calibration. Here, we attribute this odd behaviour of the isotope-humidity response to the important amount of vibration in the shelter and therefore decided to use this isotope-humidity response to calibrate the dataset. Indeed, this response should be representative of the global behaviour of the Picarro measuring during this campaign.

To summarize, here we cannot estimate from these measurements the drift over the period of field measurement. However, we incorporate an uncertainty for this drift from the laboratory calibrations. These laboratory calibrations were realized on a period longer than the campaign and therefore should bracket the actual drift of our instrument during field deployment and decrease the accuracy of the measurement to $1 \%$ in $\delta^{18} \mathrm{O}$ and $8 \%$ in $\delta \mathrm{D}$.

The precision on the absolute value is calculated from the largest residuals of both the laboratory and field calibration fit. It rises up to $18 \%$ ofor $\delta \mathrm{D}$ at $200 \mathrm{ppmv}$ and $1.7 \%$ for $\delta^{18} \mathrm{O}$ at 400 ppmv, with better precision at higher humidity (Fig. 4). This highlights the need for regular calibrations to obtain the best performances, unfortunately with a very high cost for this study: the lack of regular calibrations hinders by a fac- tor of 5 the precision of the measurements $(1.3 \%$ for $\delta \mathrm{D}$ in the best conditions from the Allan variance against $6 \%$ for $\delta \mathrm{D}$ from the mean residuals of the calibration). Additional information about the linearity of Picarro infrared spectrometers against the SMOW-SLAP scales at isotopic composition below the SLAP values can be found in Sect. 2.6 with the description of the measurements of the cryogenic trapping samples.

\subsection{Data post-treatment and performances}

In addition to the calibration and averaging necessary to improve the accuracy and precision of the dataset, we had to correct our data from the introduction of condensate inside the inlet. Figure 5 illustrates two of such "snow-intake" events, providing typical examples of duration and shape. Indeed, our inlet was facing the dominant wind without any protection to prevent introduction of condensates. Such protection usually requires to be heated to prevent condensation of water vapour under supersaturated conditions; however, heating would lead to sublimation of all the precipitation falling into the inlet, which would then increase the vapour content. Moreover, micro-droplets or crystals are often floating in the air on the Antarctic Plateau and reduce the efficiency of any precipitation filter. We therefore decided to remove the effect of all sorts of precipitation events through a post-treatment of our datasets. This is justified by a small number of cases (fewer than 100), clearly identified as "snow-intake" events.

A manual post-treatment was thus realized following systematic rules. All data with a specific humidity higher than $1000 \mathrm{ppmv}$ were discarded; this value was chosen as the maximum surface air temperature observed during the campaign $\left(-24.6^{\circ} \mathrm{C}\right)$ and implies a theoretical maximum saturated vapour content of $1030 \mathrm{ppmv}$. After this first posttreatment, the largest humidity measurements of $977 \mathrm{ppmv}$, slightly lower than the maximum saturated vapour content, suggested that we may have discarded only a few relevant high-humidity data in our post-processing.

All humidity peaks higher than natural variability were also discarded, using as a threshold 5 times the standard deviation in normal conditions (which is between 10 and 20 ppmv). In very few occasions (only twice during the entire campaign), a very high density of snowflakes could create a regular inflow of snow in the inlet, leading to an increase of the vapour content without peak shapes. In those cases, the amplitude and the frequency of the specific humidity variability still allowed us to distinguish precipitation introduction from the "background" vapour signal. These periods associated with important "snow-intakes" created gaps in the dataset ( $4 \mathrm{~h}$ in total). Gaps in our dataset mostly arise from calibration of the instruments and power shortages (30 to 60 min gaps) that could be filled by interpolating.

Two running averages were performed: first at 10 min resolution, without filling the gaps which correspond to approx- 

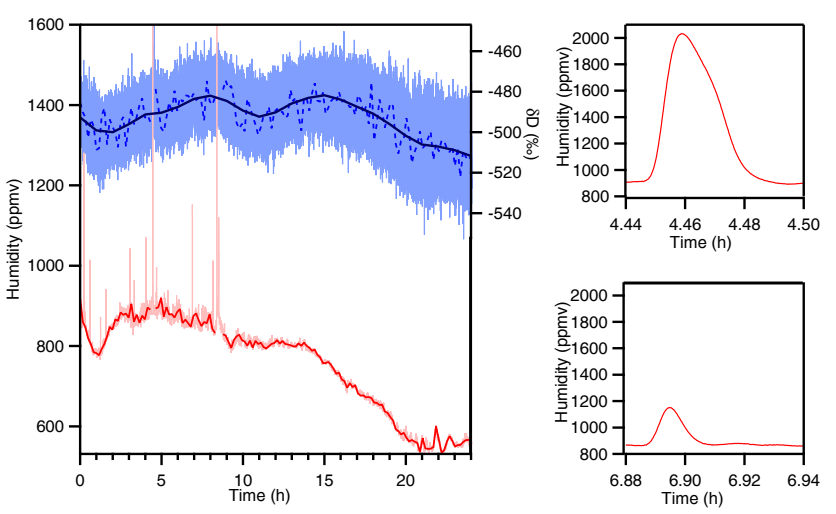

Figure 5. Left: example of raw data measured by the Picarro. Humidity (light red, ppmv) and $\delta \mathrm{D}$ (light blue, \%o), data averaged over $10 \mathrm{~min}$ for humidity (red, ppmv) and for $\delta \mathrm{D}$ (dashed line blue, \%o) and over $1 \mathrm{~h}$ for $\delta \mathrm{D}$ (dark blue, \%o). Right: zoom on two "precipitation events" identified in the humidity signal of the Picarro (top, snow flake; bottom, diamond dust).

imately $3 \%$ of the dataset (Fig. 5), then an average at a resolution of the hour where the gaps were filled by linear interpolation (only $1 \%$ of the whole datasets had gaps larger than an hour), apart from 13 January when $4 \mathrm{~h}$ in a raw were missing due to an intense precipitation event. Finally, $0.7 \%$ of the dataset is missing at the $1 \mathrm{~h}$ resolution.

Even though the spectrometer was located at the border of the clean area of the station, we verified that the influence of the station did not contaminate the vapour by analysing wind direction. As mentioned earlier, the shelter is almost $1 \mathrm{~km}$ upstream the station against the dominant wind. Few events with wind direction pointing from the station were identified ( $21 \mathrm{~h}$ spread over 5 days during the whole campaign when the wind direction is pointing from the station plus or minus $20^{\circ}$ ). Most of these events match the period when the wind speed was very low $\left(<2 \mathrm{~m} \mathrm{~s}^{-1}\right)$. We used the methane measurements also provided by the Picarro L2130 in parallel with the vapour measurements to assess any potential anthropic contamination of the vapour at the shelter area. An anthropic contamination of the vapour could lead to artificial values of isotopic composition. Indeed, combustion of fossil fuels have been shown to produce d-excess, for instance (Gorski et al., 2015). Small spikes of methane were detected for only two occurrences: 28 December between 09:30 and 10:40 and 3 January between 06:00 and 07:00 (local time). They match events with wind direction pointing at the shelter. These two events were fairly short and no specific impact on either humidity or isotopic composition can be identified for these events.

\subsection{Cryogenic trapping of the moisture}

Water vapour was trapped with a cryogenic trapping device (Craig and Gordon, 1965) consisting of a glass trap immersed in cryogenic ethanol. Cryogenic trapping has been proven reliable to trap all the moisture contained in the air and therefore to store ice samples with the same isotopic composition as the initial vapour (He and Smith, 1999; SchochFischer et al., 1983; Steen-Larsen et al., 2011; Uemura et al., 2008). Two different cryogenic trapping set-ups have been deployed. The first one, in 2006/2007, was based on traps without glass balls. These traps cannot be used with air flow above $6 \mathrm{~L} \mathrm{~min}^{-1}$ in order to trap all the moisture because the surface available for thermal transfer is rather small. In order to be certain of trapping all the moisture, two traps in series were installed. Because of the lack of glass balls, the absence of water in the trap at the end of the detrapping can be observed. This was a very important validation because detrapping efficiency is essential to obtain correct values of isotopic composition (Uemura et al., 2008). During the second campaign, we used traps filled with glass balls to increase the surface available for thermal transfer and therefore that can be used at higher flows. This cryogenic trapping set-up relies on extensive tests previous to the campaign, indicating that our custom-made glass traps filled with glass balls at $-100^{\circ} \mathrm{C}$ successfully condensate all the moisture, even for a flow up to $20 \mathrm{~L} \mathrm{~min}^{-1}$. These tests have been realized with (1) a Picarro (L2140i) to attest that the remaining humidity was below the measurement limit (around $30 \mathrm{ppmv}$ ) and (2) a second trap downstream to evaluate the presence of ice after a period of $12 \mathrm{~h}$ which would indicate a partial vapour trapping. These tests enable us to validate the system we used, similar to Steen-Larsen et al. (2011), and motivate its deployment for the second campaign at Dome C. Extensive tests have also proven that complete detrapping can be done with traps filled with glass balls despite no direct observation of possible remaining water. The results shown later on (Fig. 10) show that similar values are obtained from both types of set-up (with or without glass balls) and assess the reliability of both the methods.

Here, we present the results of two cryogenic trapping campaigns: one in 2006/2007 and one in 2014/2015. During the 2006/2007 campaign, 20 samples were gathered by cold traps (without glass balls) immersed in ethanol at $-77^{\circ} \mathrm{C}$, with a pump with a flow of $6 \mathrm{~L} \mathrm{~min}^{-1}$ and $36 \mathrm{~h}$ sampling periods. For the campaign of 2014/2015, 20 samples were gathered by cold traps (filled with glass balls) immersed in ethanol at $-100^{\circ} \mathrm{C}$ under a flow of $18 \mathrm{~L} \mathrm{~min}^{-1}$ and 10 to $14 \mathrm{~h}$ trapping periods. The samples were extracted from the traps by heating them up to $200^{\circ} \mathrm{C}$ on a line under vacuum connected to a glass phial immersed in the cryogenic ethanol for 10 to $12 \mathrm{~h}$. This process allows the total transfer of the water by forced diffusion and produces samples between 2 to $4 \mathrm{~mL}$. On 8 January 2015 , the high flux pump was damaged and was replaced by a membrane vacuum pump with only $8 \mathrm{~L} \mathrm{~min}^{-1}$ flow, increasing the trapping duration from 24 to $36 \mathrm{~h}$.

As no particles filter was installed on the inlet (cf. Sect. 2.1), we trapped both the precipitation captured by the inlet and the surface vapour. This might lead to biases 
when precipitation occurred, which must be taken into account when comparing the results between the spectrometers and the cold trap.

Samples from the 2014/2015 campaign were then shipped for laboratory analyses using a Picarro L2140i. The samples were injected through a syringe in a vaporizer and an auto-sampler. The classical calibration procedure to be analysed polar samples is using three internal standards calibrated against SMOW and SLAP: NEEM $\left(\delta^{18} \mathrm{O}=-33.56 \%\right.$ and $\left.\delta \mathrm{D}=-257.6 \%\right)$, ROSS $\left(\delta^{18} \mathrm{O}=-18.75 \% 0\right.$ and $\left.\delta \mathrm{D}=-144.6 \% \circ\right)$ and $\mathrm{OC} 3$ $\left(\delta^{18} \mathrm{O}=-54.05 \% \circ\right.$ and $\delta \mathrm{D}=-424.1 \%$ ) . The isotopic composition of the sample to analyse has to be surrounded by the isotopic composition of the standards for the calibration to be efficient. As the isotopic composition of the vapour in Concordia is well below SLAP $\left(\delta^{18} \mathrm{O}=-55.50 \% 0\right.$ and $\delta \mathrm{D}=-427.5 \%$ ), i.e. $\delta^{18} \mathrm{O}$ is around $-70 \%$, no standard was available to bracket the sample isotopic composition. It was therefore important to check the linearity of the instruments for $\delta^{18} \mathrm{O}$ values below $-55 \%$.

In order to do so, we prepared new home-made standards: we diluted a known home-made standard EPB $\left(\delta^{18} \mathrm{O}=-7.54 \pm 0.05 \%\right.$ ) with highly depleted water, Isotec water- ${ }^{16} \mathrm{O}$ from Sigma-Aldrich $\left(99.99 \%\right.$ of ${ }^{16} \mathrm{O}$ atoms, hereafter DW for depleted water). We first had to determine the absolute composition of the DW by realizing several dilutions of the water with isotopic composition in the range between SMOW and SLAP. The dilution was realized with a Sartorius ME215P scale, whose internal precision is certified at $0.02 \mathrm{mg}$. The water was injected through needles in a glass bottles covered by paraffin films to prevent evaporation. All the weights were measured four times in order to improve the precision of the measurements. From the different measurements, the accuracy is estimated at $0.1 \mathrm{mg}$ after correcting for the weight of the air removed from the bottle by injecting the water. Four new home-made standards were realized in the range SMOW-SLAP and measured 15 times each with a Picarro L2140i (cf. Fig. 6, part 1). Their isotopic composition is scattered along the line from the EPB composition to the DW composition. Because we know the exact dilution of EPB with the DW, we can use the measured $\delta^{18} \mathrm{O}$ values to precisely infer the isotopic composition of the DW: $\delta^{18} \mathrm{O}_{\mathrm{DW}}$ or $R_{\mathrm{DW}}^{18}=\left(\delta^{18} \mathrm{O}_{\mathrm{DW}} / 1000+1\right) \cdot R_{\mathrm{SMOW}}$, where $R_{\mathrm{SMOW}}^{18}=2005.2$ is the absolute isotopic composition of the SMOW in $\mathrm{H}_{2}^{18} \mathrm{O}$.

The isotopic composition of the mix is given by

$\delta^{18} \mathrm{O}_{\mathrm{mix}}=\delta^{18} \mathrm{O}_{\mathrm{EPB}}+\frac{R_{\mathrm{DW}}^{18}-R_{\mathrm{EPB}}^{18}}{R_{\mathrm{SMOW}}^{18}} X_{\mathrm{DW}}$

where $X_{\mathrm{DW}}$ is the ratio of quantities of DW vs. EPB in the dilution. The slope of the linear regression of $\delta^{18} \mathrm{O}_{\text {mix }}$ with $X_{\mathrm{DW}}$ provides directly an estimate of the isotopic composition of the DW. We find $R_{\mathrm{DW}}^{18}=128 \pm 2$ (equivalent to $\delta^{18} \mathrm{O}_{\mathrm{DW}}=-936.2 \pm 0.6 \%$ ), which is slightly less de-

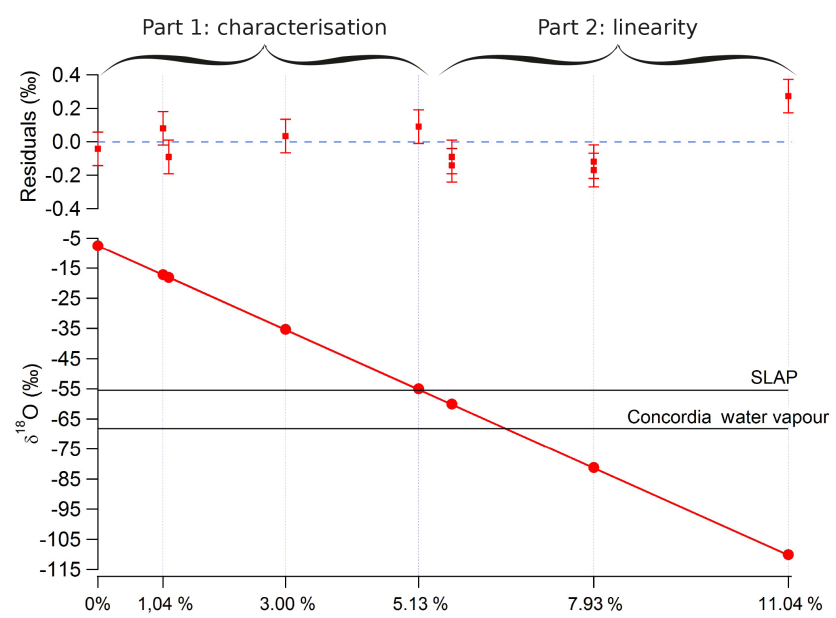

Figure 6. Isotopic composition measured by liquid injection in the Picarro L2140i for different samples prepared by dilution of EPB with "almost pure" water: the red dots are the measurements, the red line is the calculated isotopic composition and the red squares for residuals are the difference between the measurements and the theoretical composition.

pleted than the specifications given by the producer (purity of $99.99 \%)$. Another determination can be done independently by using the Eq. (1) for one single dilution. Using independent dilutions done within the range SMOW-SLAP, we obtain $R_{\mathrm{DW}}^{18}=127$ and 130 .

In a second step, we produce three other water home-made standards by dilution of EPB with "almost pure" $\mathrm{H}_{2}^{16} \mathrm{O}$ to obtain $\delta^{18} \mathrm{O}$ values below SLAP. Using the known dilution amount and the isotopic ratio of "almost pure" $\mathrm{H}_{2}^{16} \mathrm{O}$ determined above, we compare the measurements for these three home-made standards, i.e. placed on a SMOW-SLAP scale with classical calibration procedure to the values calculated using Eq. (1) (Fig. 6, part 2). Given the precision on the isotopic ratio of the "almost pure" $\mathrm{H}_{2}^{16} \mathrm{O}$, on the EPB and the precision of the scale, the precision of the calculation of $\delta^{18} \mathrm{O}_{\text {mix }}$ is $0.05 \%$ o (uncertainty propagation in Eq. 1 ).

Residuals between measured and calculated $\delta^{18} \mathrm{O}$ are less than $0.2 \%$ for the home-made standards at -60 and $-80 \%$ o and less than 0.3 at $-110 \%$. We thus conclude that the Picarro L2140i can be used safely to infer linearly $\delta^{18} \mathrm{O}$ values down to $-80 \%$, which encompasses the $\delta^{18} \mathrm{O}$ range of our water vapour samples, and is close to linear for $\delta^{18} \mathrm{O}$ values down to $-110 \%$ (deviation of $0.3 \%$ o slightly higher than the measurement uncertainty).

\section{Results}

\subsection{Validation of infrared spectrometry data}

The data gathered by the cold trap and the infrared spectrometers during the 2014/2015 campaign are displayed in Fig. 7. 


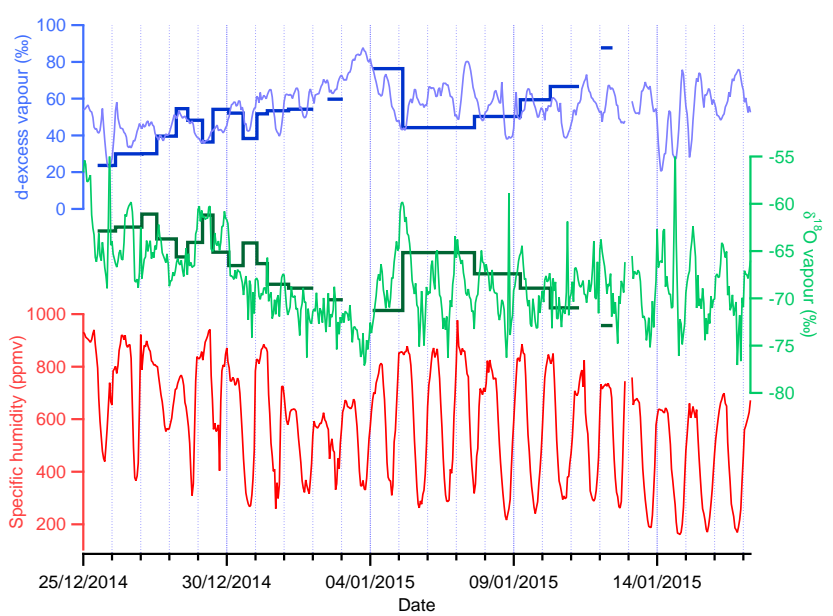

Figure 7. Hourly average $\delta^{18} \mathrm{O}(\% \circ)$ in green, raw d-excess $(\% \circ)$ in light blue (d-excess smoothed on a $3 \mathrm{~h}$ span in thick blue) and hourly average of the specific humidity (ppmv) in red during the campaign 2014/2015. Measurements by the Picarro are displayed as the thin light lines and measurements performed in the laboratory from the cold trap samples are displayed as dark bars.

The measurements performed by the Picarro (light lines) from 25 December to 4 January are marked by a $10 \%$ gradual decline in $\delta^{18} \mathrm{O}$ and a $40 \%$ gradual increase in d-excess. By contrast, the second part of the measurements (performed after 4 January) does not show any long-term multi-day trend. We also observe a decrease in $\delta^{18} \mathrm{O}$ and an increase in d-excess in the cold trap data from 25 December to 5 January. The decrease in $\delta^{18} \mathrm{O}$ and increase in d-excess are also recorded in the period from 5 January to 13 January in the cold trap results, while they are not observed in the Picarro data.

During a similar campaign in Greenland (Steen-Larsen et al., 2011), differences between infrared spectrometry in situ and cryogenic trapping measurements were generally around $0.1 \%$ in $\delta^{18} \mathrm{O}$. In comparison, we observe that the cold trap $\delta^{18} \mathrm{O}$ values are generally higher than the $\delta^{18} \mathrm{O}$ measured by the Picarro. This can be explained by several factors. First, the isotopic composition sampled using the cold trap is weighted by humidity: the cold trap traps more moisture when the humidity is highest, which also corresponds to the moment when the isotopic composition is the highest. In order to take this into account, we weighted the isotopic composition from the Picarro by specific humidity (not shown). On average, the weighted isotopic composition has an offset of $+1.1 \%$ in $\delta^{18} \mathrm{O}$ compared with the original dataset, rising up to $7.2 \%$ on 31 December and down to $-2.9 \%$ on 6 January. In this case, the cold trap $\delta^{18} \mathrm{O}$ is still in average higher than the isotopic composition weighted by humidity, with an offset of $+1.16 \%$ of $\delta^{18} \mathrm{O}$ and $-3 \%$ ofor d-excess, which lies within the error bar of our measurements. We thus conclude that, at first order, our cold trap measurements validate the laser spectrometer data.
Table 2. Average, minimum and maximum values over the whole campaign for air temperature $\left(T_{3 \mathrm{~m}}\right)$, snow surface temperature $\left(T_{\text {surf }}\right)$, specific humidity $(q), \delta \mathrm{D}(\% \circ), \delta^{18} \mathrm{O}(\% \circ)$ and $3 \mathrm{~h}$ smoothed d-excess $(\% o)$.

\begin{tabular}{lrrr}
\hline & Average & Minimum & Maximum \\
\hline$T_{3 \mathrm{~m}}\left({ }^{\circ} \mathrm{C}\right)$ & -31.2 & -42.6 & -24.6 \\
$T_{\text {surf }}\left({ }^{\circ} \mathrm{C}\right)$ & -31.5 & -46.1 & -21.2 \\
$q(\mathrm{ppmv})$ & 589 & 161 & 977 \\
$\delta \mathrm{D}(\% \circ)$ & -491 & -558 & -393 \\
$\delta^{18} \mathrm{O}(\% \circ)$ & -68.2 & -77.1 & -53.9 \\
$\mathrm{~d}-\mathrm{ex}(\% \circ)$ & 55.1 & 21 & 88 \\
\hline
\end{tabular}

The cold trap measurements may also include snow-intake events that were captured by the inlet, whereas we removed such data in the spectrometer measurements. Because the isotopic composition of precipitation is enriched compared to the vapour, the introduction of snow crystals in the cold trap inlet could explain a small part of the positive offset of cold trap measurements compared to the infrared spectrometry. No quantitative estimation of this bias has been realized.

\subsection{Two climatic regimes}

Figure 8 presents the specific humidity and isotopic composition $\left(\delta^{18} \mathrm{O}, \delta \mathrm{D}\right.$ and d-excess) measured by the Picarro. The data are continuous from 25 December 2014 to 17 January 2015 , except for $4 \mathrm{~h}$ on 13 January due to a large snowfall event. These data are compared with the $3 \mathrm{~m}$ temperature and the $3 \mathrm{~m}$ wind speed (Sect. 2.1) and also to the surface temperature monitored by infrared sensing. Note that the different temperature measurements are not intercalibrated and may present a limited bias of $1^{\circ} \mathrm{C}$. Table 2 summarizes the average, minimum and maximum values for $3 \mathrm{~m}$ temperature, surface temperature, humidity and isotopic composition.

Even though the sun never actually passes below the horizon, when the zenithal angle is low, snow surface radiation deficit generates a strong radiative cooling of the surface, which leads to stratification of the atmospheric boundary layer. Daily cycles are clearly visible in all the variables. Greater diurnal temperature variations are observed at the surface than at $3 \mathrm{~m}$ even though average temperatures remain similar as already observed in Kohnen (van As et al., 2006). Day temperature at the surface rises up to $8{ }^{\circ} \mathrm{C}$ higher than at $3 \mathrm{~m}$ during the period from 26 December 2014 to 4 January 2015. After 4 January, differences remain small (less than $2{ }^{\circ} \mathrm{C}$ ). This first difference will lead us to distinguish the two regimes to further investigate: the first one from 26 December 2014 to 4 January 2015, and the second one from 5 to 17 January 2015.

Table 3 compares the average values, the diurnal amplitudes and the trends within the different datasets. Temperature is higher during regime 1 , probably due to the proxim- 


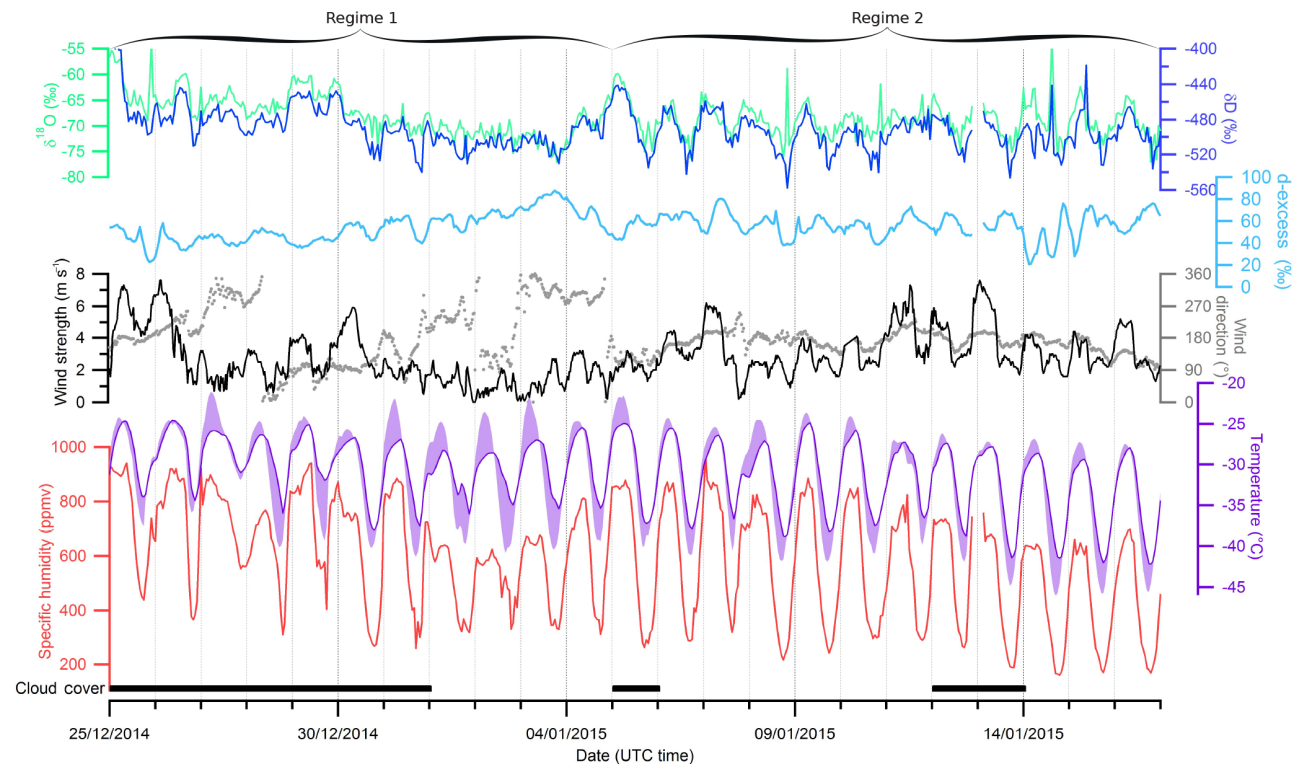

Figure 8. Hourly average $\delta \mathrm{D}(\% \circ)$ in dark blue, hourly average $\delta^{18} \mathrm{O}\left(\%_{0}\right)$ in green, d-excess (\%o) smoothed on a $3 \mathrm{~h}$ span in light blue and hourly average of the specific humidity (ppmv) in red, measured by the Picarro during the campaign; comparison with $3 \mathrm{~m}$ temperature (purple, ${ }^{\circ} \mathrm{C}$ ), difference between ground and $3 \mathrm{~m}$ temperature (purple shade, ${ }^{\circ} \mathrm{C}$ ), wind direction (grey dots, ${ }^{\circ}$ ) and speed (black line).

ity to the solar solstice. Diurnal amplitudes in air temperature and humidity are significantly higher in regime 2 than in regime 1 . In regime 1 , isotopic daily cycles are dumped and completely erased from 1 to 3 January, whereas daily cycles are important for regime 2 (in phase with those of temperature); a significant day-to-day trend appears during regime 1 with almost $-1 \%$ day ${ }^{-1}$ for $\delta^{18} \mathrm{O}$ and is not present in regime $2\left(0.07 \%\right.$ o day ${ }^{-1}$ for $\left.\delta^{18} \mathrm{O}\right)$.

We attribute the difference between the two regimes to changes in atmospheric stability, in particular during the "night". Indeed, during daytime, the convection enables strong mixing in both regime 1 and regime 2 . However, significant differences are noticeable in the nocturnal stability between regime 1 and 2 which impact the night-time turbulent mixing.

Atmospheric static stability is further assessed using the Richardson number (Richardson, 1920), which is a ratio between the square of the Brunt-Väisälä frequency $(N=$ $\sqrt{\frac{g}{\theta} \frac{\mathrm{d} \theta}{\mathrm{d} z}}$, where $\theta=T\left(P_{0} / P\right)^{R / C_{P}}$ is the potential temperature calculated from $P_{0}$ the standard reference pressure, $R$ the gas constant of air and $c_{P}$ the specific heat capacity) and the square of the horizontal wind gradient (see Supplement part 3). During regime 1, the Richardson number experiences important daily cycles, rising higher than 0.2 during night-time, indicating a stable and well-stratified boundary layer, and dropping lower than 0 during daytime, indicating a non-stable, convective atmosphere (King et al., 2006). The Richardson number is in particular really large for the nights from 1 to 3 January (rising up to 0.85 ) highlighting an enhanced night-time stratification during this period. Regime
1 is thus characterized by a well-marked diurnal cycle with a convective activity during the "day" and a stably stratified atmospheric boundary layer during the "night". By contrast, the Richardson number is lower during the night in regime 2, which leads to smaller diurnal cycles of stratification. This can be explained by stronger winds during the nights in regime 2 (Fig. 9), which enhance the turbulent mixing in the atmospheric boundary layer and tend to reduce the stratification.

We now investigate the mean daily cycle of all data during each regime. For this purpose, the trend is removed by subtracting the average value of the day from all data. We then produce a mean value for each hour of the day over the whole regime. The correlations between the average daily cycles of isotopic composition, $3 \mathrm{~m}$ temperature, $3 \mathrm{~m}$ wind speed and surface temperature are given on Table 4 . Temperature of $3 \mathrm{~m}$ is less strongly correlated with surface temperature during regime 1 compared to regime 2 . During night-time in regime 2, the atmosphere is more turbulent and therefore atmospheric mixing is more efficient. For a more stratified nocturnal atmosphere (regime 1), we expect surface temperature to be less correlated to $3 \mathrm{~m}$ temperature and also to isotopic composition.

We also observe that the correlation of surface isotopic composition and temperature, as well as between $\delta^{18} \mathrm{O}$ and $\delta \mathrm{D}$, is stronger for regime 2 (turbulent nocturnal atmosphere) than for regime 1 (stratified nocturnal atmosphere). An explanation for this correlation could be the temperature influence on the fractionation at the snow-air interface. In the case of regime 2 , as the turbulence allows efficient air mass mixing, the isotopic composition at $2 \mathrm{~m}$ is directly related to what 
Table 3. Average, daily amplitude and daily trend over the whole campaign for air temperature $\left(T_{3 \mathrm{~m}},{ }^{\circ} \mathrm{C}\right)$, snow surface temperature $\left(T_{\text {surf }}\right.$, $\left.{ }^{\circ} \mathrm{C}\right)$, specific humidity $(q, \mathrm{ppmv}), \delta \mathrm{D}(\% \circ), \delta^{18} \mathrm{O}(\% \circ)$ and smoothed d-excess $(\% \circ)$.

\begin{tabular}{lrrrrrrr}
\hline & \multicolumn{2}{c}{ Regime 1: from 26 Dec to 4 Jan } & & \multicolumn{3}{c}{ Regime 2: from 5 to 17 Jan } \\
\cline { 2 - 3 } \cline { 6 - 8 } & Average & Amplitude & Trend (/day) & & Average & Amplitude & Trend (/day) \\
\hline$T_{3 \mathrm{~m}}\left({ }^{\circ} \mathrm{C}\right)$ & -29.9 & $7.6 \pm 0.2$ & $-0.29 \pm 0.02$ & & -32.4 & $11.9 \pm 0.2$ & $-0.38 \pm 0.02$ \\
$T_{\text {surf }}\left({ }^{\circ} \mathrm{C}\right)$ & -30.2 & $14.2 \pm 0.4$ & $-0.34 \pm 0.05$ & & -32.6 & $16.2 \pm 0.3$ & $-0.47 \pm 0.03$ \\
$q(\mathrm{ppmv})$ & 631 & $341 \pm 20$ & $-24 \pm 3$ & & 541 & $521 \pm 13$ & $-39 \pm 2$ \\
$\delta \mathrm{D}(\% \circ)$ & -490 & $14 \pm 3$ & $-3.7 \pm 0.4$ & & -495 & $38 \pm 2$ & $-0.8 \pm 0.3$ \\
$\delta^{18} \mathrm{O}(\% \circ)$ & -68.1 & $1.4 \pm 0.6$ & $-0.92 \pm 0.06$ & & -68.9 & $5.4 \pm 0.4$ & $-0.07 \pm 0.04$ \\
$\mathrm{~d}-\mathrm{ex}(\% \circ)$ & 54.9 & $8 \pm 1$ & $3.7 \pm 0.2$ & & 56.2 & $13 \pm 2$ & $-0.2 \pm 0.2$ \\
\hline
\end{tabular}

Table 4. Slope and correlation coefficient between the different data average daily cycle: for each data, the average of the day was removed and a trend-free daily cycle for each regime was produced.

\begin{tabular}{|c|c|c|c|c|}
\hline & \multicolumn{2}{|c|}{$\begin{array}{c}\text { Regime 1: } \\
\text { from 26 Dec to } 4 \text { Jan }\end{array}$} & \multicolumn{2}{|c|}{$\begin{array}{c}\text { Regime } 2 \text { : } \\
\text { from } 5 \text { to } 17 \text { Jan }\end{array}$} \\
\hline & Slope & $r^{2}$ & Slope & $r^{2}$ \\
\hline$\delta \mathrm{D}(\% \mathrm{o})$ vs. $q(\mathrm{ppmv})$ & $0.043 \pm 0.005$ & 0.79 & $0.071 \pm 0.003$ & 0.96 \\
\hline$\delta \mathrm{D}(\% o)$ vs. $T_{3 \mathrm{~m}}\left({ }^{\circ} \mathrm{C}\right)$ & $2.0 \pm 0.2$ & 0.74 & $3.2 \pm 0.2$ & 0.94 \\
\hline$\delta \mathrm{D}(\% o)$ vs. $T_{\text {surf }}\left({ }^{\circ} \mathrm{C}\right)$ & $0.95 \pm 0.2$ & 0.58 & $2.3 \pm 0.1$ & 0.95 \\
\hline$\delta \mathrm{D}(\% \circ)$ vs. $\delta^{18} \mathrm{O}(\% \circ)$ & $6.0 \pm 1.3$ & 0.48 & $6.5 \pm 0.6$ & 0.85 \\
\hline$q($ ppmv $)$ vs. $T_{3 \mathrm{~m}}\left({ }^{\circ} \mathrm{C}\right)$ & $45 \pm 2$ & 0.94 & $44 \pm 2$ & 0.96 \\
\hline$q$ (ppmv) vs. $T_{\text {surf }}\left({ }^{\circ} \mathrm{C}\right)$ & $24 \pm 2$ & 0.89 & $32 \pm 1$ & 0.98 \\
\hline$T_{3 \mathrm{~m}}\left({ }^{\circ} \mathrm{C}\right)$ vs. $T_{\text {surf }}\left({ }^{\circ} \mathrm{C}\right)$ & $0.49 \pm 0.05$ & 0.80 & $0.69 \pm 0.04$ & 0.92 \\
\hline
\end{tabular}

is happening at the surface; hence the isotopic composition is strongly correlated to surface temperature. Such a situation was already described at the NEEM station in Greenland (Steen-Larsen et al., 2013), where similar temperature and water vapour isotopic composition cycles were observed during 10 days, leading to the conclusion that the snow surface was acting successively as a sink during the night and as a source during the day. They also hypothesized that the vapour isotopic composition could be at equilibrium with the snow one, at least during part of the day. Exchange with the vapour could also have strong impact on snow metamorphism in Concordia, as observed in NEEM (Steen-Larsen et al., 2014a).

In the case of regime 1 , when atmosphere is at least part of the time stratified, the mixing of the first layers of the atmosphere is not efficiently done by turbulence. In these situations happening mostly at night, the ground is cooling faster than the air above it, creating vertical gradients in moisture content of the atmosphere (van As and van den Broeke, 2006).

We now investigate the timing of the average diurnal cycles (Fig. 9). By comparing the position of the maximal slope (which enables a more precise determination of dephasing than the maxima), we notice a shift of approximately $2 \mathrm{~h}$ between surface and $3 \mathrm{~m}$ temperature. Specific humidity average daily cycle is synchronized with $3 \mathrm{~m}$ temperature in both regimes 1 and 2. For regime 1, no diurnal cycle appears in surface vapour isotopic composition. For regime 2, the daily cycle of surface vapour isotopic composition is synchronized with surface temperature and therefore shifted $2 \mathrm{~h}$ earlier than $3 \mathrm{~m}$ temperature and humidity. This is consistent with the hypothesis of temperature-driven exchanges of molecules between the air and the snow surface in regime 2 . This hypothesis will be discussed in more details in part 3.3 .

The diurnal amplitude that we measured $(38 \%$ ofor $\delta \mathrm{D}$ in average during regime 2) is within the range obtained in previous studies in Greenland. In NEEM, daily cycles up to $36 \%$ for $\delta \mathrm{D}$ were measured during summer campaigns (Steen-Larsen et al., 2013), much more important than those cycles on the coastal areas of Greenland with peak-to-peak amplitudes of variations of $1 \%$ for $\delta^{18} \mathrm{O}$ in Ivittuut, Greenland (Bonne et al., 2014). A similar pattern is observed around Antarctica, near coastal areas, on a ship near Syowa station, where isotopic composition variations are dominated by day-to-day evolution and there are no diurnal cycles $(\mathrm{Ku}-$ rita et al., 2016).

\subsection{Local water vapour $\delta \mathrm{D}-\delta^{18} \mathrm{O}$ relationship and snow surface interactions}

Figure 10 presents the $\delta \mathrm{D}$ and $\delta^{18} \mathrm{O}$ isotopic composition during the 2014/2015 campaign, for continuous measurements and cold trap data, and earlier cold trap data from 

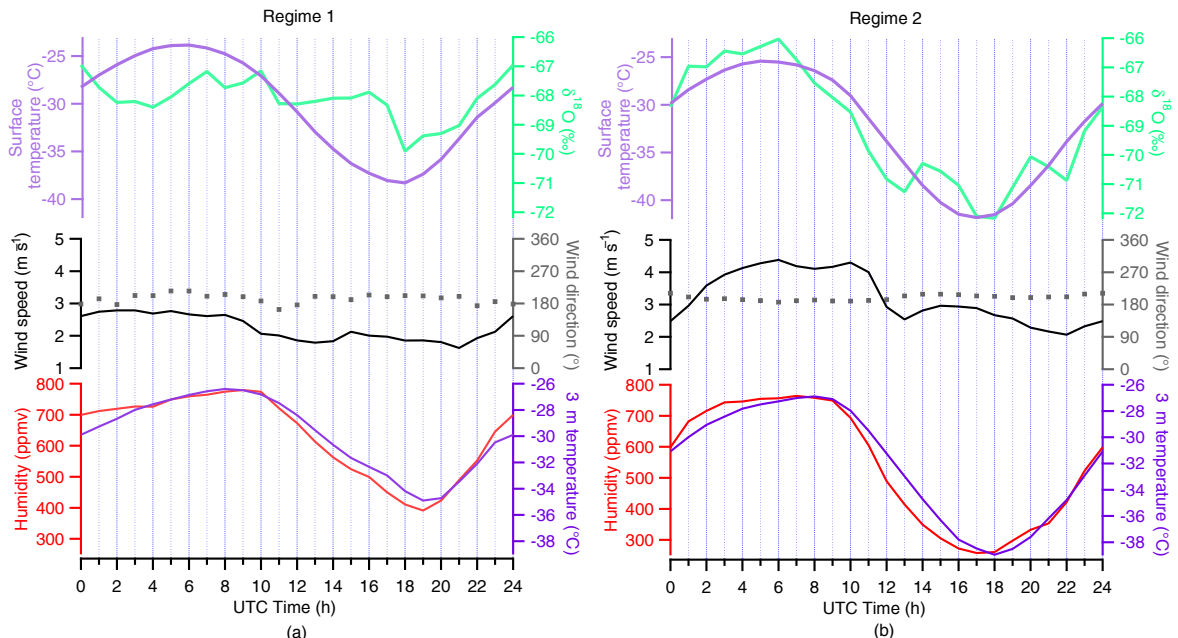

Figure 9. Comparison of average daily cycles (UTC time) of $3 \mathrm{~m}$ temperature (light purple, ${ }^{\circ} \mathrm{C}$ ), surface temperature (dark purple), specific humidity (red, ppmv), wind speed (black line, $\mathrm{m} \mathrm{s}^{-1}$ ), wind direction (black dots, ${ }^{\circ}$ ) and $\delta^{18} \mathrm{O}$ (green, \%o) for (a) regime 1 and (b) regime 2 .

2006/2007. We observe that all these data depict a common range of isotopic composition and align on a similar slope. In this section, we focus on the slope between $\delta \mathrm{D}$ and $\delta^{18} \mathrm{O}$ and not on the d-excess. Indeed, the high values of d-excess are related to the low value of the slope $\delta \mathrm{D}$ vs. $\delta^{18} \mathrm{O}$ (around 5 compared to the value of 8 used in the d-excess calculation). Note that discussions of d-excess or of the slope between $\delta \mathrm{D}$ and $\delta^{18} \mathrm{O}$ are strictly equivalent in this case.

We observe very low (around 5) $\delta \mathrm{D}$ and $\delta^{18} \mathrm{O}$ slopes measured using on-site infrared spectroscopy and post-campaign mass spectrometry of the cryogenic trapping samples (Table 5). In fact, publication of the 2006/2007 cold trap data was postponed until an explanation for such low vapour line was identified due to the fear of sampling vapour from the station generator. As stated in Sect. 2.5, no such contamination occurred. This slope is much lower than observed in Greenland (Bonne et al., 2014; Steen-Larsen et al., 2013). A very low slope for $\delta \mathrm{D}$ vs. $\delta^{18} \mathrm{O}$ in water vapour is not unexpected as Dome $\mathrm{C}$ is very far on the distillation path and air masses are very depleted in heavy isotopologues (Touzeau et al., 2016). Indeed, for a Rayleigh distillation, the local relative variations of the isotopic composition of $\delta \mathrm{D}$ and $\delta^{18} \mathrm{O}$ are defined by

$\frac{\mathrm{d} \delta \mathrm{D}}{\mathrm{d} \delta^{18} \mathrm{O}}=\frac{\alpha_{\mathrm{D}}-1}{\alpha_{18}-1} \frac{1+\delta \mathrm{D}}{1+\delta^{18} \mathrm{O}}$,

where $\alpha_{\mathrm{D}}$ and $\alpha_{18}$ are respectively the equilibrium fractionation coefficients of $\mathrm{HDO}$ and $\mathrm{H}_{2}^{18} \mathrm{O}$ (Jouzel and Merlivat, 1984). In the average condition of the campaign $\left(T=-31.5^{\circ} \mathrm{C}\right.$ and isotopic composition from Table 2), even if $\left(\alpha_{\mathrm{D}}-1\right) /\left(\alpha_{18}-1\right)=9.71$, the very low value of $\delta \mathrm{D}$ (around $-500 \%$ ) brings down the slope $\delta \mathrm{D}$ and $\delta^{18} \mathrm{O}$ to $5.3 \% 0 \% 0^{-1}$. Note that the important d-excess values obtained in Sect. 3.2. are due to the very low slope between $\delta \mathrm{D}$ and

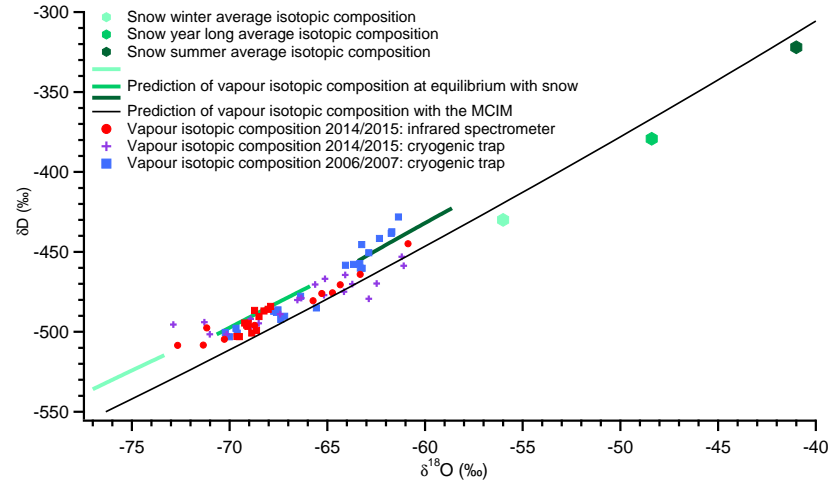

Figure 10. $\delta \mathrm{D}$ and $\delta^{18} \mathrm{O}$ plots: red is the daily average isotopic composition from the Picarro (circles: regime 1; squares: regime 2), purple crosses are the cold trap isotopic composition from 2014/2015 campaign, blue squares are the cold trap isotopic composition from 2006/2007, green hexagons are the isotopic composition of the snow (Touzeau et al., 2015) (light tone is the average composition minus 1 standard deviation, mid-tone is the average composition and dark tone is the average composition plus 1 standard deviation), green lines are the respecting calculated equilibrium fractionation in the range of temperature observed during the campaign (Majoube, 1971) (local origin thereafter) and the black line is the curve established with a Rayleigh distillation in the MCIM (remote origin thereafter).

$\delta^{18} \mathrm{O}$ and not necessarily to important kinetic effects in this case.

We now discuss in details the possible drivers of the isotopic composition of water vapour at Dome $\mathrm{C}$ following several hypotheses: the first being local origin (equilibrium between surface snow and water vapour), the second being remote origin (distillation of a water mass from the coast). 
Table 5. Slope and correlation coefficients between the different datasets. Picarro and meteorological data are daily average data. Equilibrium fractionation slopes are calculated from the average values (average, \pm 1 standard deviation) with Majoube fractionation coefficients (high M, med M, low M) or Ellehøj fractionation coefficients (med E).

\begin{tabular}{|c|c|c|c|}
\hline & & \multicolumn{2}{|c|}{ Data for all season } \\
\hline & & Slope & $r^{2}$ \\
\hline \multirow[t]{6}{*}{ Picarro data } & $\delta \mathrm{D}(\% \circ)$ vs. $q(\mathrm{ppmv})$ & $0.12 \pm 0.02$ & 0.61 \\
\hline & $\delta \mathrm{D}(\% \circ)$ vs. $T_{3 \mathrm{~m}}\left({ }^{\circ} \mathrm{C}\right)$ & $3.7 \pm 1.5$ & 0.22 \\
\hline & $\delta \mathrm{D}(\% \circ)$ vs. $T_{\text {surf }}\left({ }^{\circ} \mathrm{C}\right)$ & $4.3 \pm 1.2$ & 0.30 \\
\hline & $\delta \mathrm{D}(\% o)$ vs. $\delta^{18} \mathrm{O}(\% \circ)$ & $5.3 \pm 0.3$ & 0.92 \\
\hline & $q$ (ppmv) vs. $T_{3 \mathrm{~m}}\left({ }^{\circ} \mathrm{C}\right)$ & $43 \pm 6$ & 0.69 \\
\hline & $q$ (ppmv) vs. $T_{\text {surf }}\left({ }^{\circ} \mathrm{C}\right)$ & $45 \pm 5$ & 0.79 \\
\hline Meteological data & $T_{3 \mathrm{~m}}\left({ }^{\circ} \mathrm{C}\right)$ vs. $T_{\text {surf }}\left({ }^{\circ} \mathrm{C}\right)$ & $0.7 \pm 0.1$ & 0.63 \\
\hline Trapping 2006/2007 & $\delta \mathrm{D}(\% \circ)$ vs. $\delta^{18} \mathrm{O}(\% \circ)$ & $4.6 \pm 0.7$ & 0.82 \\
\hline Trapping 2014/2015 & $\delta \mathrm{D}(\% \circ)$ vs. $\delta^{18} \mathrm{O}(\% \circ)$ & $4.8 \pm 0.4$ & 0.90 \\
\hline \multirow[t]{4}{*}{ Equilibrium fractionation } & $\delta \mathrm{D}(\% \circ)$ vs. $\delta^{18} \mathrm{O}(\% \circ)$ high $\mathrm{M}$ & 7.02 & Th. \\
\hline & $\delta \mathrm{D}(\% o)$ vs. $\delta^{18} \mathrm{O}(\% \circ)$ med $\mathrm{M}$ & 6.50 & Th. \\
\hline & $\delta \mathrm{D}(\% \circ)$ vs. $\delta^{18} \mathrm{O}(\% o)$ low $\mathrm{M}$ & 5.99 & Th. \\
\hline & $\delta \mathrm{D}(\% \circ)$ vs. $\delta^{18} \mathrm{O}(\% \circ)$ med $\mathrm{E}$ & 5.65 & Th. \\
\hline MCIM & $\delta \mathrm{D}(\% \circ)$ vs. $\delta^{18} \mathrm{O}(\% \circ)$ at $-35^{\circ} \mathrm{C}$ & 6.11 & Th. \\
\hline
\end{tabular}

For the first hypothesis, we used the range of annual isotopic composition of the snow at Dome $\mathrm{C}$ (Touzeau et al., 2016), represented by green hexagons (average value \pm 1 standard deviation). The slope between $\delta \mathrm{D}$ and $\delta^{18} \mathrm{O}$ of the snow annual isotopic composition is $7.2 \% 0 \% o^{-1}$, already lower than 8 . From these values, we calculate the corresponding vapour isotopic composition in the range of summer temperature $\left(-20\right.$ to $\left.-45^{\circ} \mathrm{C}\right)$ using standard equilibrium fractionation coefficients (Majoube, 1971; Merlivat and Nief, 1967). The range of calculated vapour isotopic contents is consistent with observed vapour: from the average value of snow $\delta^{18} \mathrm{O}=-48.4 \%$, we get a vapour predicted $\delta^{18} \mathrm{O}=-68.2 \%$ at $-35^{\circ} \mathrm{C}$, which lies within the values measured by the Picarro (on average over the campaign $\delta^{18} \mathrm{O}=-68.9 \%$ ). The slope between $\delta \mathrm{D}$ and $\delta^{18} \mathrm{O}$, however, is higher than the one observed: $6.5 \% 0 \% 0^{-1}$ vs. $5.3 \% 0 \% o^{-1}$ for the Picarro and even $4.8 \% 0 \% 0^{-1}$ for the cold traps. The same calculation with the equilibrium fractionation coefficients from Ellehøj et al. (2013) can predict relevant $\delta^{18} \mathrm{O}$ and $\delta \mathrm{D}$ values and more realistic slopes $\left(5.7 \% \circ \% o^{-1}\right)$.

We now analyse the effect of the distillation on the isotopic composition of the water vapour. For this test, we used the Mixed Cloud Isotopic Model (MCIM) to compute the isotopic composition of the vapour. The MCIM is a Rayleigh model taking into account microphysical properties of clouds and in particular accounting for mixed phases (Ciais and Jouzel, 1994). The model was tuned with snow isotopic composition of an Antarctic transect from Terra Nova Bay to Dome $\mathrm{C}$ to accurately reproduce the isotopic composition of the Antarctic Plateau (Winkler et al., 2012). For instance, the model predicts an average value of snow isotopic composition at Dome $\mathrm{C}$ of $-51 \%$ for an average site temperature of $-54.5^{\circ} \mathrm{C}$ when the measurements indicated $-50.7 \%$; note that the model takes into account an inversion temperature and that the condensation temperature $T_{\text {cond }}$ is deduced from the surface temperature $T_{\text {surf }}$ through (Ekaykin and Lipenkov, 2009)

$T_{\text {cond }}=0.67 \times T_{\text {surf }}-1.2$.

The prediction of average vapour isotopic composition by the MCIM is $\delta^{18} \mathrm{O}=-51.6 \%$ at $-35^{\circ} \mathrm{C}$, which is much higher than the average vapour measurements $\left(\delta^{18} \mathrm{O}=-68.9 \%\right.$ ). However, the MCIM manages to predict the isotopic composition of the summer precipitation $\left(\delta^{18} \mathrm{O}=-37 \%\right.$ at $-35^{\circ} \mathrm{C}$ for the model compared to values rising up to $-39 \%$ ofor matching temperature in Dome $\mathrm{C}$ summer precipitation). Therefore, we conclude that the vapour isotopic composition seems to be principally influenced by local effects. Note that the slope between $\delta \mathrm{D}$ and $\delta^{18} \mathrm{O}$ predicted by the MCIM is around $6.1 \% \circ \% o^{-1}$, which is also higher than the one observed during the campaign (between 4.6 and 5.3 for the different datasets).

The precipitation amount in Dome $C$ is less than $10 \mathrm{~cm}$ per year (Genthon et al., 2015). Each precipitation event does not form a complete layer of snow and is mixed with earlier snowfall possibly deposited under the earlier winter conditions. The snow isotopic composition is therefore a mix of new snowfall and older snow. This phenomenon is amplified by drift and blowing snow (Libois et al., 2014). A mixing be- 
tween a large range of source isotopic compositions should be considered to compute the local origin hypotheses, which could explain the bias of the slope predicted by equilibrium from a single snow composition compared to experimental data.

\section{Conclusion}

In this study, we assessed the relevance of infrared spectrometry to measure isotopic composition of water at concentrations as low as those encountered over the Antarctic Plateau. Apart from the logistic challenges involved in the installation of spectrometers in remote areas, humidity levels, very depleted samples and important local variability create a technical challenge that the new infrared spectroscopy techniques overcame.

Allan variance measurements in the laboratory indicated the possibility of using Picarro and HiFI spectrometers at humidity as low as $200 \mathrm{ppmv}$ and with almost no loss of precision from $500 \mathrm{ppmv}$ (limit of precision of $0.1 \% \circ \delta^{18} \mathrm{O}$ and for $1.1 \%$ ofor $\delta \mathrm{D})$. Identical measurements in the field showed it was possible to reach similar results in the field even though great care in the environment where the instruments are deployed should be addressed.

For such humidities, the linearity of the instruments is not guaranteed toward humidity and regular calibrations in the field are necessary. In this particular study, it was not possible to calibrate the instruments regularly in the field for logistical reasons, so we bracketed the drift of the instrument by series of calibration in the lab. This is not the optimal method and results in significant error bars compared to the performances of the instrument. The uncertainty of the isotopic composition measurement is therefore $6 \%$ for $\delta \mathrm{D}$ and $1 \%$ for $\delta^{18} \mathrm{O}$. We have further validated these measurements through (i) a comparison of the data acquired by infrared spectrometry with cryogenic trapping samples and (ii) a protocol to calibrate on the SMOW-SLAP scale at $\delta^{18} \mathrm{O}$ lower than the SLAP $\delta^{18} \mathrm{O}$ value $(-55.5 \%$ ). This calibration demonstrated that our Picarro instrument is linear in $\delta^{18} \mathrm{O}$, down to $-80 \%$ in $\delta^{18} \mathrm{O}$ and stays almost linear down to $-110 \%$. This is essential for our study since the mean $\delta^{18} \mathrm{O}$ value was $-68.2 \%$ at Concordia between 25 December 2014 and 17 January 2015.

Two different regimes have been identified during the campaign: the first from 26 December 2014 to 4 January 2015 and the second from 5 to 17 January 2015. The main difference between the two regimes on isotopic composition is the amplitude of the daily cycles: large and regular during regime 2, small and irregular in regime 1 and an almost erased one from 1 to 4 January 2015. For regime 1, correlation of humidity with surface temperature is lowered and isotopic composition is almost stable, whereas for regime 2 there is an almost perfect correlation for both humidity and isotopic composition with temperature. We attribute these differences to differences in the stability of the atmosphere. We explain the drop of correlation in regime 1 by a weakly turbulent boundary layer during which temperature, humidity and isotopic composition diurnal cycles are truncated in comparison to regime 2 , which is characterized by efficient turbulence with important diurnal cycles and almost perfect correlation between the snow surface temperature and the first metres of the atmosphere. The second regime therefore appears to be characterized by equilibrium between the isotopic composition of vapour over the first metres and that of the snow, as already shown for Greenland (Steen-Larsen et al., 2013).

Temperature cycles seem to be directly responsible for isotopic composition cycles, at least in regime 2, through equilibrium fractionation in sublimation/condensation cycles. At first order, it seems the snow isotopic composition is influencing directly the vapour through fractionation at phase change. The vapour isotopic composition average value matches the one obtained by equilibrium fractionation of the local snow. However, the measured slope between $\delta \mathrm{D}$ and $\delta^{18} \mathrm{O}$ still cannot be explained purely by equilibrium fractionation from local snow. We cannot rule out a contribution of horizontal air advection from inland locations, transported by southward winds and providing small amounts of very depleted moisture.

Finally, our study opens new perspectives on the influence of post-deposition effects and their importance for the water stable isotope signal recorded in deep ice cores. In particular, we have shown that the relationship between water vapour $\delta^{18} \mathrm{O}$ and temperature can be erased by weakly turbulent regimes. Yearlong monitoring of the isotopic composition of the water vapour could help identify how often these conditions happen and also whether the snow isotopic composition could present a biased relationship toward seasonality, temperature or precipitation.

\section{Data availability}

The dataset used for this study is available as a Supplement.

\section{The Supplement related to this article is available online at doi:10.5194/acp-16-8521-2016-supplement.}

Author contributions. Mathieu Casado, Amaelle Landais, Frederic Prie, Samir Kassi and Peter Cermak prepared the field campaign; Mathieu Casado deployed the instruments on the field; Valérie Masson-Delmotte, Erik Kerstel and Samir Kassi provided the infrared spectrometers; Christophe Genthon, Laurent Arnaud, Ghislain Picard, Olivier Cattani and Etienne Vignon provided data; Mathieu Casado prepared the manuscript with contributions from all co-authors. 
Acknowledgements. The research leading to these results has received funding from the European Research Council under the European Union's Seventh Framework Programme (FP7/20072013)/ERC grant agreement no. 306045. We acknowledge the programs NIVO and GLACIO and all the IPEV that made this campaign possible and LGGE and LIPHY for providing logistic advice and support. We thank Catherine Ritz, Anais Orsi and Xavier Fain for their help during the preparation of the mission. Many thanks to Philippe Ricaud, Doris Thuillier, Nicolas Caillon, Bruno Jourdain, Olivier Magand and all the 11th winter-over team for your support and your presence in Concordia. Thanks to Hubert Gallée for all the discussions about polar meteorology.

Edited by: Y. Balkanski

\section{References}

Aemisegger, F., Sturm, P., Graf, P., Sodemann, H., Pfahl, S., Knohl, A., and Wernli, H.: Measuring variations of $\delta^{18} \mathrm{O}$ and $\delta^{2} \mathrm{H}$ in atmospheric water vapour using two commercial laser-based spectrometers: an instrument characterisation study, Atmos. Meas. Tech., 5, 1491-1511, doi:10.5194/amt-5-1491-2012, 2012.

Bailey, A., Noone, D., Berkelhammer, M., Steen-Larsen, H. C., and Sato, P.: The stability and calibration of water vapor isotope ratio measurements during long-term deployments, Atmos. Meas. Tech., 8, 4521-4538, doi:10.5194/amt-8-4521-2015, 2015.

Bonne, J.-L., Masson-Delmotte, V., Cattani, O., Delmotte, M., Risi, C., Sodemann, H., and Steen-Larsen, H. C.: The isotopic composition of water vapour and precipitation in Ivittuut, southern Greenland, Atmos. Chem. Phys., 14, 4419-4439, doi:10.5194/acp-14-4419-2014, 2014.

Bonne, J.-L., Steen-Larsen, H. C., Risi, C., Werner, M., Sodemann, H., Lacour, J.-L., Fettweis, X., Cesana, G., Delmotte, M., Cattani, O., Vallelonga, P., Kjær, H. A., Clerbaux, C., Sveinbjörnsdóttirffilmark, Á. E., and Masson-Delmotte, V.: The summer 2012 Greenland heat wave: in situ and remote sensing observations of water vapour isotopic composition during an atmospheric river event, J. Geophys. Res.-Atmos., 120, 2970-2989, 2015.

Cappa, C. D., Hendricks, M. B., DePaolo, D. J., and Cohen, R. C.: Isotopic fractionation of water during evaporation, J. Geophys. Res.-Atmos., 108, 4525, doi:10.1029/2003JD003597, 2003.

Charles, C. D., Rind, D., Jouzel, J., Koster, R. D., and Fairbanks, R. G.: Glacial-Interglacial Changes in Moisture Sources for Greenland: Influences on the Ice Core Record of Climate, Science, 263, 508-511, 1994.

Ciais, P. and Jouzel, J.: Deuterium and oxygen 18 in precipitation: Isotopic model, including mixed cloud processes, J. Geophys. Res.-Atmos., 99, 16793-16803, 1994.

Craig, H. and Gordon, A.: Deuterium and oxygen 18 variations in the ocean and the marine atmosphere, Stable Isotopes in Oceanic Studies and Paleotemperatures, edited by: Tongiorgi, E., 9-130, Laboratorio di Geologia Nucleare, Pisa, 1965.

Crosson, E. R.: A cavity ring-down analyzer for measuring atmospheric levels of methane, carbon dioxide, and water vapor, Appl. Phys. B, 92, 403-408, 2008.

Dansgaard, W.: Stable isotopes in precipitation, Tellus, 16, 436468, 1964.
Ekaykin, A. A. and Lipenkov, V. Y.: Formation of the ice core isotopic composition, Low Temperature Science, 68, 299-314, 2009.

Ekaykin, A. A., Lipenkov, V. Y., Barkov, N. I., Petit, J. R., and Masson-Delmotte, V.: Spatial and temporal variability in isotope composition of recent snow in the vicinity of Vostok station, Antarctica: implications for ice-core record interpretation, Ann. Glaciol., 35, 181-186, 2002.

Ekaykin, A. A., Lipenkov, V. Y., Kuzmina, I. N., Petit, J. R., Masson-Delmotte, V., and Johnsen, S. J.: The changes in isotope composition and accumulation of snow at Vostok station, East Antarctica, over the past 200 years, Ann. Glaciol., 39, 569-575, 2004.

Ellehøj, M. D., Steen-Larsen, H. C., Johnsen, S. J., and Madsen, M. B.: Ice-vapor equilibrium fractionation factor of hydrogen and oxygen isotopes: Experimental investigations and implications for stable water isotope studies, Rapid Commun. Mass Sp., 27, 2149-2158, 2013.

EPICA: Eight glacial cycles from an Antarctic ice core, Nature, 429, 623-628, 2004.

Fawcett, P. J., Ágústsdóttir, A. M., Alley, R. B., and Shuman, C. A.: The Younger Dryas Termination and North Atlantic Deep Water Formation: Insights from climate model simulations and Greenland Ice Cores, Paleoceanography, 12, 23-38, 1997.

Frezzotti, M., Gandolfi, S., La Marca, F., and Urbini, S.: Snow dunes and glazed surfaces in Antarctica: new field and remotesensing data, Ann. Glaciol., 34, 81-88, 2002.

Genthon, C., Town, M. S., Six, D., Favier, V., Argentini, S., and Pellegrini, A.: Meteorological atmospheric boundary layer measurements and ECMWF analyses during summer at Dome C, Antarctica, J. Geophys. Res.-Atmos., 115, 2156-2202, doi:10.1029/2009JD012741, 2010.

Genthon, C., Six, D., Favier, V., Lazzara, M., and Keller, L.: Atmospheric Temperature Measurement Biases on the Antarctic Plateau, J. Atmos. Ocean. Tech., 28, 1598-1605, 2011.

Genthon, C., Six, D., Gallée, H., Grigioni, P., and Pellegrini, A.: Two years of atmospheric boundary layer observations on a 45$\mathrm{m}$ tower at Dome $\mathrm{C}$ on the Antarctic plateau, J. Geophys. Res.Atmos., 118, 3218-3232, 2013.

Genthon, C., Six, D., Scarchilli, C., Ciardini, V., and Frezzotti, M.: Meteorological and snow accumulation gradients across Dome C, East Antarctic plateau, Int. J. Climatol., 36, 455-466, 2015.

Gorski, G., Strong, C., Good, S. P., Bares, R., Ehleringer, J. R., and Bowen, G. J.: Vapor hydrogen and oxygen isotopes reflect water of combustion in the urban atmosphere, P. Natl. Acad. Sci. USA, 112, 3247-3252, 2015.

He, H. and Smith, R. B.: Stable isotope composition of water vapor in the atmospheric boundary layer above the forests of New England, J. Geophys. Res.-Atmos., 104, 11657-11673, 1999.

Hoshina, Y., Fujita, K., Nakazawa, F., Iizuka, Y., Miyake, T., Hirabayashi, M., Kuramoto, T., Fujita, S., and Motoyama, H.: Effect of accumulation rate on water stable isotopes of near-surface snow in inland Antarctica, J. Geophys. Res.-Atmos., 119, 274 283, 2014.

IAEA: Reference Sheet for VSMOW2 and SLAP2 international measurement standards. International Atomic Energy Agency, Vienna, 2009.

Johnsen, S. J., Clausen, H. B., Cuffey, K. M., Hoffmann, G., and Creyts, T. T.: Diffusion of stable isotopes in polar firn and ice: 
the isotope effect in firn diffusion, Physics of ice core records, 159, 121-140, 2000.

Jouzel, J. and Merlivat, L.: Deuterium and oxygen 18 in precipitation: Modeling of the isotopic effects during snow formation, $\mathrm{J}$. Geophys. Res.-Atmos., 89, 11749-11757, 1984.

Jouzel, J., Alley, R., Cuffey, K., Dansgaard, W., Grootes, P., Hoffmann, G., Johnsen, S., Koster, R., Peel, D., and Shuman, C.: Validity of the temperature reconstruction from water isotopes in ice cores, J. Geophys. Res., 102, 26471-26487, 1997.

Jouzel, J., Delaygue, G., Landais, A., Masson-Delmotte, V., Risi, C., and Vimeux, F.: Water isotopes as tools to document oceanic sources of precipitation, Water Resour. Res., 49, 7469-7486, 2013.

King, J. C., Argentini, S. A., and Anderson, P. S.: Contrasts between the summertime surface energy balance and boundary layer structure at Dome C and Halley stations, Antarctica, J. Geophys. Res.-Atmos., 111, D02105, doi:10.1029/2005JD006130, 2006.

Krinner, G., Genthon, C., and Jouzel, J.: GCM analysis of local influences on ice core $\delta$ signals, Geophys. Res. Lett., 24, 28252828, 1997.

Kurita, N., Hirasawa, N., Koga, S., Matsushita, J., Steen-Larsen, H. C., Masson-Delmotte, V., and Fujiyoshi, Y.: Influence of largescale atmospheric circulation to marine air intrusion on the East Antarctic coast, Geophys. Res. Lett., under review, 2016.

Landais, A., Barkan, E., and Luz, B.: Record of $\delta^{18} \mathrm{O}$ and ${ }^{17} \mathrm{O}$-excess in ice from Vostok Antarctica during the last 150,000 years, Geophys. Res. Lett., 35, L02709, doi:10.1029/2007GL032096, 2008.

Landsberg, J.: Development of an OF-CEAS laser spectrometer for water vapor isotope measurements at low water concentrations, University of Groningen, 2014.

Landsberg, J., Romanini, D., and Kerstel, E.: Very high finesse optical-feedback cavity-enhanced absorption spectrometer for low concentration water vapor isotope analyses, Opt. Lett., 39, 1795-1798, 2014.

LeGrande, A. N. and Schmidt, G. A.: Global gridded data set of the oxygen isotopic composition in seawater, Geophys. Res. Lett., 33, L12604, doi:10.1029/2006GL026011, 2006.

Libois, Q., Picard, G., Arnaud, L., Morin, S., and Brun, E.: Modeling the impact of snow drift on the decameter-scale variability of snow properties on the Antarctic Plateau, J. Geophys. Res.Atmos., 119, 11662-11681, 2014.

Lorius, C., Merlivat, L., and Hagemann, R.: Variation in the mean deuterium content of precipitations in Antarctica, J. Geophys. Res., 74, 7027-7031, 1969.

Luz, B., Barkan, E., Yam, R., and Shemesh, A.: Fractionation of oxygen and hydrogen isotopes in evaporating water, Geochim. Cosmochim. Ac., 73, 6697-6703, 2009.

Majoube, M.: Fractionation in O-18 between ice and water vapor, J. Chim. Phys. PCB, 68, 625-636, 1971.

Masson-Delmotte, V., Hou, S., Ekaykin, A., Jouzel, J., Aristarain, A., Bernardo, R. T., Bromwich, D., Cattani, O., Delmotte, M., Falourd, S., Frezzotti, M., Gallée, H., Genoni, L., Isaksson, E., Landais, A., Helsen, M. M., Hoffmann, G., Lopez, J., Morgan, V., Motoyama, H., Noone, D., Oerter, H., Petit, J. R., Royer, A., Uemura, R., Schmidt, G. A., Schlosser, E., Simões, J. C., Steig, E. J., Stenni, B., Stievenard, M., van den Broeke, M. R., van de Wal, R. S. W., van de Berg, W. J., Vimeux, F., and White, J. W.
C.: A Review of Antarctic Surface Snow Isotopic Composition: Observations, Atmospheric Circulation, and Isotopic Modeling*, J. Climate, 21, 3359-3387, 2008.

Masson-Delmotte, V., Buiron, D., Ekaykin, A., Frezzotti, M., Gallée, H., Jouzel, J., Krinner, G., Landais, A., Motoyama, H., Oerter, H., Pol, K., Pollard, D., Ritz, C., Schlosser, E., Sime, L. C., Sodemann, H., Stenni, B., Uemura, R., and Vimeux, F.: A comparison of the present and last interglacial periods in six Antarctic ice cores, Clim. Past, 7, 397-423, doi:10.5194/cp-7397-2011, 2011.

Merlivat, L.: Molecular diffusivities of $\left(\mathrm{H}_{2} \mathrm{O}\right)-\mathrm{O}^{16} \mathrm{HD}^{16} \mathrm{O}$, and $\left(\mathrm{H}_{2} \mathrm{O}\right)-\mathrm{O}^{18}$ in gases, J. Chem. Phys., 69, 2864-2871, 1978.

Merlivat, L. and Nief, G.: Fractionnement isotopique lors des changements d'état solide-vapeur et liquide-vapeur de l'eau à des températures inférieures à $0^{\circ} \mathrm{C}$, Tellus, 19, 122-127, 1967.

Neumann, T. A. and Waddington, E. D.: Effects of firn ventilation on isotopic exchange, J. Glaciol., 50, 183-194, 2004.

Petit, J. R., Jouzel, J., Pourchet, M., and Merlivat, L.: A detailed study of snow accumulation and stable isotope content in Dome C (Antarctica), J. Geophys. Res.-Oceans, 87, 4301-4308, 1982.

Ricaud, P., Genthon, C., Durand, P., Attié, J. L., Carminati, F., Canut, G., Vanacker, J. F., Moggio, L., Courcoux, Y., Pellegrini, A., and Rose, T.: Summer to Winter Diurnal Variabilities of Temperature and Water Vapour in the Lowermost Troposphere as Observed by HAMSTRAD over Dome C, Antarctica, Bound.-Lay. Meteorol., 143, 227-259, 2012.

Richardson, L. F.: The Supply of Energy from and to Atmospheric Eddies, P. Roy. Soc. Lond. A, 97, 354-373, 1920.

Risi, C., Bony, S., Vimeux, F., and Jouzel, J.: Water-stable isotopes in the LMDZ4 general circulation model: Model evaluation for present-day and past climates and applications to climatic interpretations of tropical isotopic records, J. Geophys. Res.-Atmos., 115, D12118, doi:10.1029/2009JD013255, 2010.

Romanini, D., Ventrillard, I., Méjean, G., Morville, J., and Kerstel, E.: Introduction to Cavity Enhanced Absorption Spectroscopy, in: Cavity-Enhanced Spectroscopy and Sensing, edited by: Gagliardi, G. and Loock, H.-P., Springer Berlin Heidelberg, 1-60, 2014.

Röthlisberger, R., Hutterli, M. A., Sommer, S., Wolff, E. W., and Mulvaney, R.: Factors controlling nitrate in ice cores: Evidence from the Dome C deep ice core, J. Geophys. Res.-Atmos., 105, 20565-20572, 2000.

Salisbury, J. W., Wald, A., and D'Aria, D. M.: Thermal-infrared remote sensing and Kirchhoff's law: 1. Laboratory measurements, J. Geophysical Res.-Sol. Ea., 99, 11897-11911, 1994.

Schmidt, G. A., Hoffmann, G., Shindell, D. T., and Hu, Y.: Modeling atmospheric stable water isotopes and the potential for constraining cloud processes and stratosphere-troposphere water exchange, J. Geophys. Res.-Atmos., 110, D21314, doi:10.1029/2005JD005790, 2005.

Schneebeli, M. and Sokratov, S. A.: Tomography of temperature gradient metamorphism of snow and associated changes in heat conductivity, Hydrol. Process., 18, 3655-3665, 2004.

Schoch-Fischer, H., Rozanski, K., Jacob, H., Sonntag, C., Jouzel, I., Östlund, G., and Geyh, M.: Hydrometeorological factors controlling the time variation of $\mathrm{D},{ }^{18} \mathrm{O}$ and ${ }^{3} \mathrm{H}$ in atmospheric water vapour and precipitation in the northern westwind belt, IAEA, Isotope Hydrology, Vienna, IAEA, 3-30, 1983. 
Sokratov, S. A. and Golubev, V. N.: Snow isotopic content change by sublimation, J. Glaciol., 55, 823-828, 2009.

Steen-Larsen, H. C., Masson-Delmotte, V., Sjolte, J., Johnsen, S. J., Vinther, B. M., Bréon, F. M., Clausen, H. B., Dahl-Jensen, D., Falourd, S., Fettweis, X., Gallée, H., Jouzel, J., Kageyama, M., Lerche, H., Minster, B., Picard, G., Punge, H. J., Risi, C., Salas, D., Schwander, J., Steffen, K., Sveinbjörnsdóttir, A. E., Svensson, A., and White, J.: Understanding the climatic signal in the water stable isotope records from the NEEM shallow firn/ice cores in northwest Greenland, J. Geophys. Res.-Atmos., 116, D06108, doi:10.1029/2010JD014311, 2011.

Steen-Larsen, H. C., Johnsen, S. J., Masson-Delmotte, V., Stenni, B., Risi, C., Sodemann, H., Balslev-Clausen, D., Blunier, T., Dahl-Jensen, D., Ellehøj, M. D., Falourd, S., Grindsted, A., Gkinis, V., Jouzel, J., Popp, T., Sheldon, S., Simonsen, S. B., Sjolte, J., Steffensen, J. P., Sperlich, P., Sveinbjörnsdóttir, A. E., Vinther, B. M., and White, J. W. C.: Continuous monitoring of summer surface water vapor isotopic composition above the Greenland Ice Sheet, Atmos. Chem. Phys., 13, 4815-4828, doi:10.5194/acp-13-4815-2013, 2013.

Steen-Larsen, H. C., Masson-Delmotte, V., Hirabayashi, M., Winkler, R., Satow, K., Prié, F., Bayou, N., Brun, E., Cuffey, K. M., Dahl-Jensen, D., Dumont, M., Guillevic, M., Kipfstuhl, S., Landais, A., Popp, T., Risi, C., Steffen, K., Stenni, B., and Sveinbjörnsdottír, A. E.: What controls the isotopic composition of Greenland surface snow?, Clim. Past, 10, 377-392, doi:10.5194/cp-10-377-2014, 2014a.

Steen-Larsen, H. C., Sveinbjörnsdottir, A. E., Peters, A. J., MassonDelmotte, V., Guishard, M. P., Hsiao, G., Jouzel, J., Noone, D., Warren, J. K., and White, J. W. C.: Climatic controls on water vapor deuterium excess in the marine boundary layer of the North Atlantic based on 500 days of in situ, continuous measurements, Atmos. Chem. Phys., 14, 7741-7756, doi:10.5194/acp-14-77412014, 2014b.

Touzeau, A., Landais, A., Stenni, B., Uemura, R., Fukui, K., Fujita, S., Guilbaud, S., Ekaykin, A., Casado, M., Barkan, E., Luz, B., Magand, O., Teste, G., Le Meur, E., Baroni, M., Savarino, J., Bourgeois, I., and Risi, C.: Acquisition of isotopic composition for surface snow in East Antarctica and the links to climatic parameters, The Cryosphere Discuss., 9, 6275-6313, doi:10.5194/tcd-9-6275-2015, 2015.
Touzeau, A., Landais, A., Stenni, B., Uemura, R., Fukui, K., Fujita, S., Guilbaud, S., Ekaykin, A., Casado, M., Barkan, E., Luz, B., Magand, O., Teste, G., Le Meur, E., Baroni, M., Savarino, J., Bourgeois, I., and Risi, C.: Acquisition of isotopic composition for surface snow in East Antarctica and the links to climatic parameters, The Cryosphere, 10, 837-852, doi:10.5194/tc-10-8372016, 2016.

Tremoy, G., Vimeux, F., Cattani, O., Mayaki, S., Souley, I., and Favreau, G.: Measurements of water vapor isotope ratios with wavelength-scanned cavity ring-down spectroscopy technology: new insights and important caveats for deuterium excess measurements in tropical areas in comparison with isotope-ratio mass spectrometry, Rapid Commun. Mass Sp., 25, 3469-3480, 2011.

Uemura, R., Matsui, Y., Yoshimura, K., Motoyama, H., and Yoshida, N.: Evidence of deuterium excess in water vapor as an indicator of ocean surface conditions, J. Geophys. Res.-Atmos., 113, D19114, doi:10.1029/2008JD010209, 2008.

van As, D. and van den Broeke, M. R.: Structure and dynamics of the summertime atmospheric boundary layer over the Antarctic Plateau: 2. Heat, moisture, and momentum budgets, J. Geophys. Res.-Atmos., 111, D07103, doi:10.1029/2005JD006956, 2006.

van As, D., van den Broeke, M. R., and Helsen, M. M.: Structure and dynamics of the summertime atmospheric boundary layer over the Antarctic Plateau: 1. Measurements and model validation, J. Geophys. Res.-Atmos., 111, D07102, doi:10.1029/2005JD005948, 2006.

Van Hook, W. A.: Vapor pressures of the isotopic waters and ices, J. Phys. Chem., 72, 1234-1244, 1968.

Waddington, E. D., Steig, E. J., and Neumann, T. A.: Using characteristic times to assess whether stable isotopes in polar snow can be reversibly deposited, Ann. Glaciol., 35, 118-124, 2002.

Werner, M., Langebroek, P. M., Carlsen, T., Herold, M., and Lohmann, G.: Stable water isotopes in the ECHAM5 general circulation model: Toward high-resolution isotope modeling on a global scale, J. Geophys. Res.-Atmos., 116, D15109, doi:10.1029/2011JD015681, 2011.

Winkler, R., Landais, A., Sodemann, H., Dümbgen, L., Prié, F., Masson-Delmotte, V., Stenni, B., and Jouzel, J.: Deglaciation records of ${ }^{17} \mathrm{O}$-excess in East Antarctica: reliable reconstruction of oceanic normalized relative humidity from coastal sites, Clim. Past, 8, 1-16, doi:10.5194/cp-8-1-2012, 2012. 